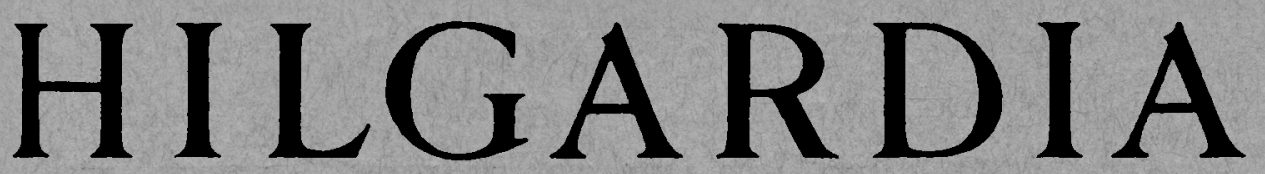

A Journal of Agricultural Science Publisbed by the California Agricultural Experiment Station

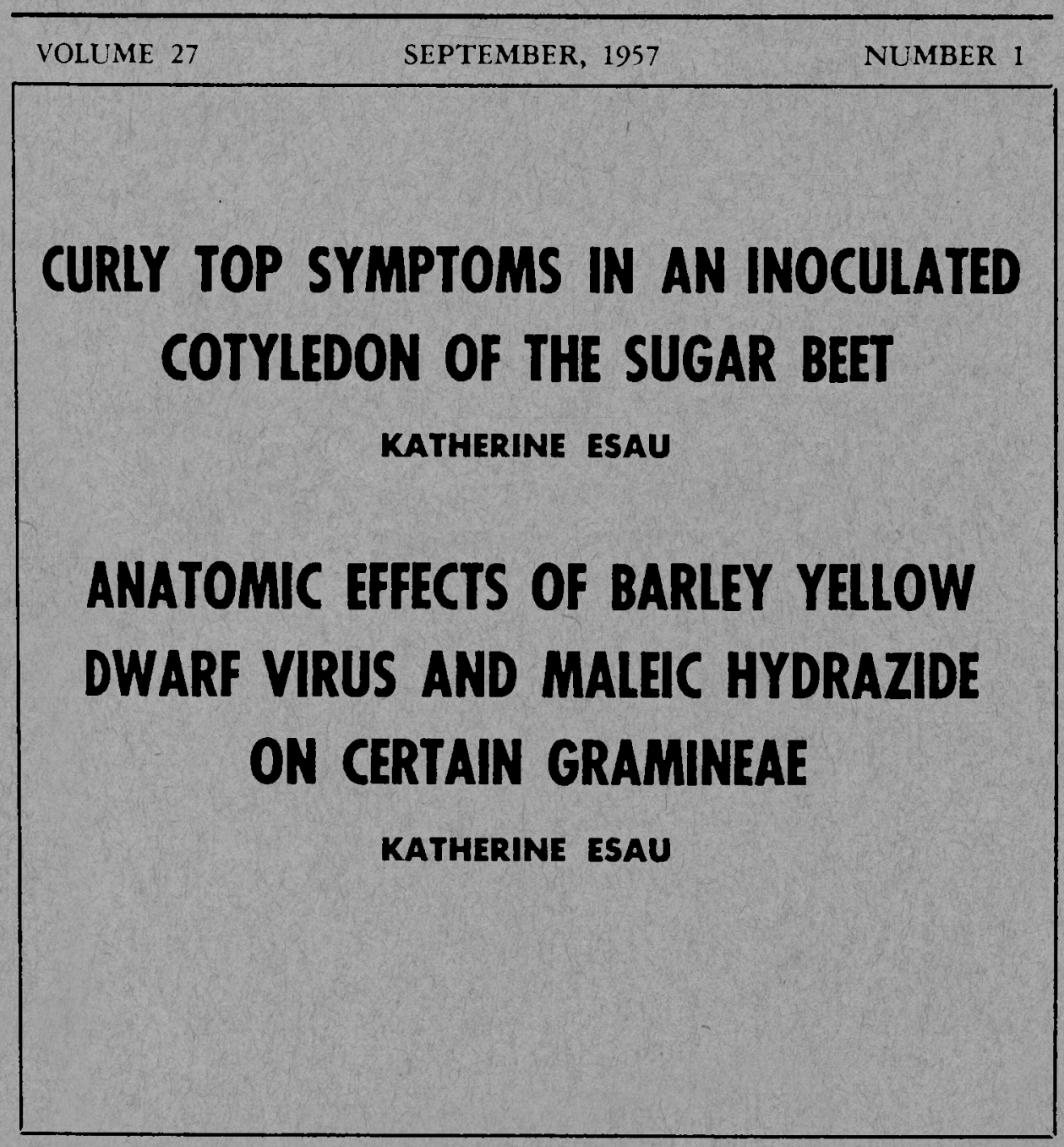

UNIVERSITY OF CALIFORNIA • BERKELEY, CALIFORNIA 


\section{CURLY TOP SYMPTOMS IN AN INOCULATED COTYLEDON OF THE SUGAR BEET}

Virus of curly top disease was introduced, through one cotyledon, into seedlings of a highly susceptible sugar beet strain. The inoculated cotyledon developed phloem hyperplasia-abnormal multiplication of cells-characteristic of the curly top disease. This symptom was observed in the main vein and some small veins on the third day after inoculation. In many samples, the main vascular bundle also showed pronounced necrotic obliteration in the older part of the phtoem tissue, a symptom not previously described for curly top infection.

Noninoculated cotyledons collected twelve days after inoculation of the experimental seedlings had developed no curly top symptoms.

\section{ANATOMIC EFFECTS OF BARLEY YELLOW DWARF VIRUS AND MALEIC HYDRAZIDE ON CERTAIN GRAMINEAE}

Infection with the virus of barley yellow dwarf disease and treatment with maleic hydrazide produce many similar external and internal degenerative changes. These are depression of growth, the yellowing of leaves, the forming of sugary exudate on leaves, and the necrosis of certain tissues, particularly of the phloem.

A significant difference exists between the initial effect of the virus and that of maleic hydrazide in the growing parts of shoot and root. Virus injury is first recognized, anatomically, in the young phloem, whereas the first effect of maleic hydrazide is expressed in the inhibition of meristematic activity. The initial derangement in the phloem induced by the virus is of such a nature that the existence of a close relation between the virus and the phloem may be inferred: the virus seems to move in the mature sieve elements. Maleic hydrazide does not appear to be primarily associated with the phloem, but it also probably enters this tissue (the phloem) since in older phloem it induces degenerative changes similar to those found in the yellow dwarf plants. 


\section{ANATOMIC EFFECTS OF BARLEY YELLOW DWARF VIRUS AND MALEIC HYDRAZIDE ON CERTAIN GRAMINEAE}

\section{KATHERINE ESAU ${ }^{2}$}

\section{INTRODUCTION}

STUDIEs of the anatomy of plants affected by viruses are of utmost importance in determining the relation of viruses to the tissues of the host. If approached from the developmental standpoint, such studies may reveal the primary pathologic changes in the infected.plant and thus indicate the tissue or tissues mainly affected by the virus. Anatomic studies have aided materially in the recognition of viruses that are more or less closely limited to the phloem and xylem tissues, as contrasted with viruses distributed in all tissues of the plant (see reviews by Esau, 1948, 1956)..$^{3}$ Information on the anatomic changes in diseased plants helps in the understanding of at least some of the viral diseases (e.g., Sheffield, 1943).

Many virus-disease symptoms-internal as well as external-resemble changes induced in plants by the application of growth-regulating substances. Such changes are: deformations of leaves and flowers; inhibition of growth (hypoplasia), on the one hand, stimulation of abnormal growth (hypertrophy and hyperplasia), on the other; destruction of chloroplasts; necrosis in various tissues, including the vascular tissues. Comparisons of anatomic effects of viruses with those induced by growth-regulating substances should be of value for elucidating the nature of virus injury, especially in view of the evidence that a relation exists between viruses and the activities of growth-regulating substances in the infected plants (e.g., Jahnel, 1937, 1939; Pavillard, 1953).

Maleic hydrazide, which is sometimes classified as a growth-regulating (Currier et al., 1951), sometimes as strictly a growth-inhibiting substance (Naylor and Davis, 1950; Nickell, 1953), brings about changes that in certain respects resemble the symptoms induced by the barley yellow dwarf virus. ${ }^{4}$ The depression of growth, the yellowing of leaves, the sugary exudate on leaves, and, finally, the necrosis of certain tissues, particularly of the phloem, are effects common to the yellow dwarf virus and the maleic hydrazide.

The present study was undertaken to determine the primary and secondary anatomic changes induced by the yellow dwarf virus in its various hosts and to compare these changes with those brought about by a treatment with maleic hydrazide. The yellow dwarf virus induces phloem degeneration that appears to be a primary symptom. The principal features of this degeneration have been reported (Esau, 1957a). Additional details on the changes in

\footnotetext{
${ }^{1}$ Received for publication February 25, 1957.

${ }^{2}$ Professor of Botany and Botanist in the Experiment Station, Davis.

${ }^{3}$ See "Literature Cited" for citations referred to in text by author and date.

"To simplify the writing, the term "barley yellow dwarf virus" is further abbreviated to "yellow dwarf virus" and the disease is referred to as "yellow dwarf disease" or simply "yellow dwarf," regardless of the host. Such usage is a compromise because the term "yellow dwarf" does not properly describe the symptoms in certain Gramineae (cf. Oswald and Houston, 1953a, $b$ ).
} 
the phloem, as well as a description of the effects upon other tissues are given in the present paper. Some cytological and anatomical effects of maleic hydrazide upon the barley plant were investigated by Gifford (1956). The present study on the effect of maleic hydrazide has added significant details to the picture of phloem degeneration and has brought out the differences and similarities between the pathologic effects of the yellow dwarf virus and maleic hydrazide.

\section{MATERIAL AND METHODS}

The study of the effects of the yellow dwarf virus was divided in two parts. In 1951-1952 the material consisted of barley plants of the Black Hulless and California Mariout varieties that were used by Dr. J. W. Oswald and Dr. B. R. Houston of the Department of Plant Pathology at Davis for their various studies on relations of the virus to the vectors. Different species of aphid were employed. The plants were inoculated 6 to 10 days after the seed was planted and the symptoms appeared 12 to 14 days after the inoculation. The plants were sampled for the anatomic study 20 to 80 days after the inoculation, when they showed severe stunting.

The second part of the study, initiated in 1954, was extended to include several other Gramineae hosts of the virus and to obtain earlier stages in disease development than were available in the 1951-1952 collections of barley. The following species (taxonomic classification according to Hitchcock, 1951) were used: Avena fatua L. and A. sativa L. (Coast Black Oat) ; Bromus inermis Leyss., B. mollis L., and B. rigidus Roth.; Hordeum hystrix Roth. and $H$. vulgare L. (Black Hulless Barley); Phalaris paradoxa L.; Triticum aestivum L. (Baart Wheat). The plants were grown and inoculated under the supervision of Dr. B. R. Houston in the greenhouse of the Department of Plant Pathology at Davis.

At the time of inoculation the second leaf was just visible in wheat, barley, and oat. In the other species only one leaf had developed. The other details of treatment correspond to those described by Oswald and Houston (1953b). One, two, or three collections were made from each species at different times after the inoculation (cf. table 1). In this part of the study, as well as the earlier one on barley, leaves of various ages, shoot tips with several millimeters of axis below, root tips, and old roots were collected. Control material was included in each collection. Some complications developed when certain controls became accidentally infected with the virus. Also, toward the end of the experiment, some healthy and diseased plants became infected with the powdery mildew.

No collections were made at the time of inoculation. The usefulness of having the information on the number of leaves initiated at the time of inoculation (and treatment with maleic hydrazide) was not fully realized. According to Bonnett $(1935,1936,1937)$ in barley nearly all the leaves are initiated when the "second leaf is well grown" (p. 453); in the wheat plant the sixth leaf primordium was visible when the plant had two leaves, in oat the fifth. Mackie et al. (1952) found that in five-day-old barley plants, in which the first leaf still enclosed the subsequently formed leaves, four leaves had been initiated. Since in the presently described barley, oat, and wheat 
the second leaf was just emerging at the time of inoculation, one might assume that at this time between four and five leaves had been initiated in these three species.

Fully developed leaves of Avena sativa L. (Clinton Oat) affected with the red-leaf disease-a disease induced by the same virus as the yellow dwarf disease of barley (Allen, 1956; Allen and Houston, 1956; Takeshita, 1956) -were sent by Dr. R. M. Endo (formerly Takeshita) from Illinois for comparison with the material inoculated in California. Control material accompanied the diseased material. According to Dr. Endo, the leaves supplied by him had sugary exudate on the surface.

In studies with maleic hydrazide the following species were used: Avena sativa L. (Coast Black Oat); Bromus inermis Leyss. and B. rigidus Roth.; Hordeum vulgare L. (Black Hulless and California Mariout Barley). The seeds were planted in 4-inch pots in the greenhouse and the seedlings were thinned to five plants to a pot. Two weeks after planting, when the second leaf was partly visible, the plants were sprayed with a solution of 0.2 per cent maleic hydrazide (as the diethanolamine salt). Vatsol (American Cyanamid Company) at 0.05 per cent concentration was added as a spreader. The plants, placed on a slowly revolving platform, were sprayed from a fixed position with an atomizer (De Vilbiss No. 261), oscillated by hand. The amount of spray used-10 ec of solution to a pot-was sufficient to wet the plants thoroughly. In one experiment collections were made 9,14 , and 21 days after the treatment (cf. table 2 ); in another, which included only barley, 5, 10, 15, and 20 days after the treatment. The samples included plant parts similar to those used in the study of the yellow dwarf disease.

An ordinary paraffin method was employed in the processing of the material for microscopic study. ${ }^{5}$ Two staining combinations were used: safraninhematoxylin and safranin-fast green. Some difficulty was experienced in obtaining a proper fixation of the mesophyll that had developed large intercellular spaces but did not yet attain maximum cell-wall rigidity. Addition of a wetting agent (Edwal Kwik-Wet) improved the fixation. The imbedded material had to be soaked before the sectioning to reduce the hardness of cell walls. The photomicrographs used for the illustrations are all from transverse sections, except figure 15 which shows longitudinal sections.

\section{EFFECTS OF YELLOW DWARF UPON THE SHOOT}

Growth of the Shoot. The external symptoms induced by yellow dwarf virus have been described for various Gramineae by Oswald and Houston $(1953 a, b)$. One of the most consistent symptoms is the stunting of the plant. In the present study the retardation of growth was verified by measurements of length of the leaf blade (table 1). In the youngest leaves, which did not show a differentiation into a blade and a sheath, the part of the leaf that was exserted from the sheaths of the older leaves was measured. (Data for certain species are not entered in table 1 because of some inadequacies in the samples.)

${ }^{5}$ Assistance with the microtechnique was given at various times by Dr. Amelie C. B. Blyth, Mrs. Celia MeElroy England, Miss Marilyn D. Christensen, Mrs. Alice W. Williams, and Miss Engracia Arguelles. 
TABLE 1

EFFECT OF YELLOW DWARF VIRUS UPON CERTAIN DEVELOPMENTAL FEATURES IN THE SHOOT

\begin{tabular}{|c|c|c|c|c|c|c|c|c|c|c|c|c|}
\hline \multirow{2}{*}{ Species and treatment } & \multicolumn{2}{|c|}{$\begin{array}{l}\text { Number of days } \\
\text { between sam- } \\
\text { pling* and }^{*}\end{array}$} & \multirow{2}{*}{$\begin{array}{c}\text { Number } \\
\text { of leaves } \\
\text { initiated } \\
\text { on the } \\
\text { plant }\end{array}$} & \multicolumn{7}{|c|}{$\begin{array}{l}\text { Length of leaf blade in } \mathrm{mm} \text { in the } \\
\text { following leaves counted from base } \\
\text { of plant upward }\end{array}$} & \multirow{2}{*}{$\begin{array}{c}\text { Number } \\
\text { of } \\
\text { microns } \\
\text { between } \\
\text { apex and } \\
\text { youngest } \\
\text { leaf }\end{array}$} & \multirow{2}{*}{$\begin{array}{l}\text { Level of } \\
\text { vascular- } \\
\text { ization } \\
\text { below } \\
\text { the } \\
\text { apex } \dagger\end{array}$} \\
\hline & $\begin{array}{c}\text { plant- } \\
\text { ing }\end{array}$ & $\begin{array}{l}\text { inocu- } \\
\text { lation }\end{array}$ & & 1 & 2 & 3 & 4 & 5 & 6 & 7 & & \\
\hline \multicolumn{13}{|l|}{ Avena sativa } \\
\hline Control. & 23 & .. & 7.8 & 118 & 182 & 194 & 0 & 0 & 0 & 0 & 95 & 4.5 \\
\hline Inoculated. & 23 & 13 & 7.0 & 112 & 142 & 0 & 0 & 0 & 0 & 0 & 70 & 4.0 \\
\hline Control. & 30 & .. & 9.0 & 100 & 152 & 266 & 146 & 0 & 0 & 0 & 94 & 4.8 \\
\hline Inoculated. . & 30 & 20 & 7.2 & 105 & 125 & 30 & 0 & 0 & 0 & 0 & 60 & 4.0 \\
\hline Control. & 37 & .. & 11.2 & 114 & 178 & 276 & 224 & 158 & 14 & 0 & 102 & 5.0 \\
\hline Inoculated.... & 37 & 27 & 8.8 & 98 & 134 & 24 & 14 & 2 & 0 & 0 & 58 & 4.0 \\
\hline \multicolumn{13}{|l|}{ Bromus inermis } \\
\hline Control.... & 26 & .. & 5.8 & 55 & 95 & 9 & 0 & 0 & 0 & 0 & 50 & 3.0 \\
\hline Inoculated.... & 26 & 13 & 5.5 & 68 & 120 & 19 & 0 & 0 & 0 & 0 & 38 & 3.3 \\
\hline Control. . & 37 & .. & 10.0 & 68 & 142 & 184 & 220 & 62 & 0 & 0 & 102 & 5.0 \\
\hline Inoculated. & 37 & 24 & 7.3 & 60 & 96 & 128 & 54 & 0 & 0 & 0 & 48 & 3.8 \\
\hline \multicolumn{13}{|l|}{ Bromus mollis } \\
\hline Control.... & 26 & . & 7.8 & 64 & 128 & 160 & 8 & 0 & 0 & 0 & 82 & 4.4 \\
\hline Inoculated. . & 26 & 13 & 7.2 & 76 & 118 & 38 & 0 & 0 & 0 & 0 & 54 & 4.0 \\
\hline Control. . & 42 & .. & 12.2 & 80 & 178 & 238 & 218 & 182 & 72 & 0 & 90 & 5.6 \\
\hline Inoculated. & 42 & 29 & 9.5 & 54 & 98 & 86 & 82 & 80 & 10 & 0 & 63 & 3.8 \\
\hline \multicolumn{13}{|l|}{ Bromus rigidus } \\
\hline Control..... & 51 & . & 16.7 & 90 & 160 & 250 & 248 & 240 & 258 & 280 & 147 & 6.7 \\
\hline Inoculated... & 51 & 41 & 13.4 & 86 & 152 & 148 & 128 & 130 & 166 & 114 & 128 & 5.5 \\
\hline \multicolumn{13}{|l|}{ Hordeum vulgare } \\
\hline Control....... & 52 & .. & $\ldots \ldots t$ & 98 & 128 & 208 & 270 & 243 & 230 & 255 & $\ldots \ddagger$ & $\ldots \ddagger$ \\
\hline Inoculated.... & 52 & 39 & $\ldots$ & 93 & 130 & 148 & 142 & 98 & 40 & 6 & $\ldots$ & $\ldots$ \\
\hline \multicolumn{13}{|l|}{ Triticum aestivum } \\
\hline Control .......... & 35 & . & $\ldots \ddagger$ & 102 & 198 & 316 & 318 & 336 & 246 & 72 & $\ldots \ddagger$ & $\ldots \ddagger$ \\
\hline Inoculated ....... & 35 & 25 & $\ldots$ & 98 & 188 & 214 & 204 & 156 & 106 & 10 & $\ldots$ & $\ldots$ \\
\hline
\end{tabular}

* Each sampling contained 4 to 5 plants, mostly 5 .

t Expressed as plastochron counted from the apex downward.

† Inflorescence was initiated.

According to table 1, the difference in length of leaf blades between the control and the inoculated material increased with the duration of the experiment and was, naturally, more noticeable in the younger than in the older leaves. The first leaf was in an advanced stage of development at the time of inoculation and, therefore, its growth was not affected by the disease. The second leaf was affected only slightly and not consistently in all species. In most collections, the pronounced retardation of growth began with the third or fourth leaf.

The stunting of the plants was evident also in the suppression of leaf initiation by the apical meristem (fourth column in table 1). The number 
of leaves initiated on the plant was determined only in those species in which the control was still in the vegetative state. In Hordeum (see fig. 6) and Triticum inflorescences were initiated.

The inhibition of leaf initiation indicates a reduction in meristematic activity. The column in table 1 giving the number of microns between the apex and the youngest leaf shows that the reduction in the activity of the apical meristem is accompanied by a reduction in its height. In other words, in the diseased plants the youngest leaf appears at a somewhat higher level than in the unaffected plants.

A common concomitant of a reduced meristematic activity is the relative elevation of the levels of differentiation of vascular tissues. If the apical meristem is inactive, xylem and phloem mature closer to the apex of the shoot or root than if a rapid growth occurs in the terminal meristem. The last column in table 1 shows that in plants affected by the yellow dwarf virus vascular elements mature at a shorter plastochronic distance from the apex than in the controls. The plastochronic distance here refers to the number of the leaf, counted from above, that shows the first mature xylem and phloem elements. The term is based on the word plastochron that denotes the time interval between two repetitive events, in this instance, between appearance of two successive leaves at the apex. Further developed, the term plastochron may be used to denote levels in the shoot.

Table 1 shows that with the progress of the disease the plastochronic distance between the apex and the leaf having mature xylem and phloem elements is reduced. Thus, in the last sampling of Avena, xylem and phloem elements occurred in leaf 4 in the infected plant, in leaf 5 in the healthy. The difference was somewhat greater in the second collection of Bromus inermis and $B$. mollis and in the one collection of $B$. rigidus. In most plants the first sieve elements not accompanied by mature xylem appeared one plastochron earlier than the combination of xylem and phloem recorded in the last column of table 1 .

Phloem Degeneration in Leaves. The principal characteristics of the vascular bundles and the phloem tissue of Gramineae have been described in connection with the first report on the pathologic changes in the phloem of Gramineae affected with yellow dwarf (Esau, 1957a). As illustrated in figure 1 , the vascular bundles vary in size. In the mature large vascular bundles (fig. 3, $A, C$ ) the active phloem (metaphloem) consists of sieve tubes $(a$ ) with companion cells $(b)$ and is bordered on the periphery by parenchyma cells $(c)$. The earlier part of the phloem (protophloem) that matures before the leaves complete their elongation is crushed and more or less completely obliterated in mature bundles. The remains of this phloem appear as relatively inconspicuous wall thickenings at the outer margin of the phloem ( $f$ in fig. 3, $A, C$ ). The xylem (metaxylem) consists of wide vessels $(e)$ and some small tracheary cells and parenchyma cells. The tracheary elements of the earliest xylem (protoxylem) are destroyed during the elongation of the leaf and are replaced by a lacuna $(d)$ surrounded by parenchyma cells.

The small vascular bundles that differentiate after the leaf has elongated show no destruction of phloem or xylem elements (fig. 4, $A, C$ ). They contain sieve elements $(a)$ with companion cells and some parenchyma cells on 
the periphery of the phloem. The xylem contains a few tracheary elements (b) and usually some parenchyma.

The main features of the phloem degeneration in Gramineae inoculated with the yellow dwarf virus (cf. Esau, 1957a) are illustrated for oat in figure 2 and for barley in figures 3,4 , and 5 . In leaves differentiating after the inoculation the degenerative changes appear soon after the first sieve elements mature (fig. 2, $A$ ). These elements and some of the adjacent parenchyma cells become necrosed and collapse $(f)$. This phenomenon has been termed necrotic obliteration (Esau, 1957a) to contrast it with the normal obliteration of phloem elements. It involves an accumulation of material-probably wound gum - that stains red with safranin (fig. 5, B). The subsequently

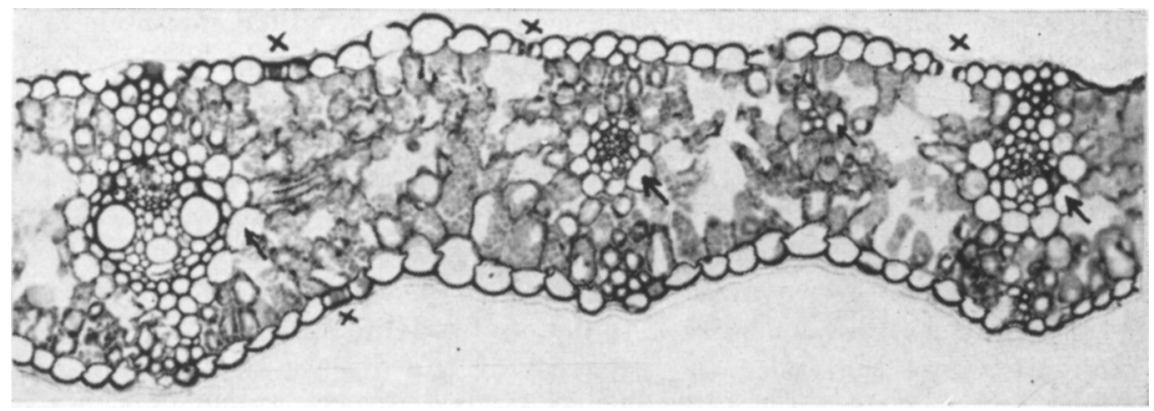

Fig. 1. Hordeum vulgare, barley. Leaf blade showing median vascular bundle to left and three other bundles of various sizes. The phloem is above, the xylem below in each bundle. The vascular tissues of bundles are enclosed in bundle sheaths, an inner sheath with thickened cell walls (the endodermoid sheath) and an outer sheath (arrows) with thin cell walls and few chloroplasts. Mesophyll cells with chloroplasts constitute ground tissue of blade. The epidermis contains stomata (marked by crosses) on both surfaces of leaf. From a plant free of symptoms collected in a field. $(\times 136$.

developing phloem and the phloem that is already differentiated at the time of infection are also affected. The companion cells and the parenchyma cells become more deeply stained than in normal leaves (fig. $2, B$; fig. $3, B, D$ ) and some of them become necrosed. The sieve elements often contain gummous material in their lumina (fig. $3, D, a$ ). Necrotic obliteration of different degrees of intensity is evident in the older bundles (fig. $2, B, C ;$ fig. $3, B, D$ ), usually more intense in a somewhat younger (fig. $2, C$ ) than in an older leaf (fig. 2, $B$ ). The small vascular bundles that normally show no phloem obliteration, exhibit necrotic obliteration of various degrees in affected plants (fig. $4, B, D)$.

The growth of the whole bundle is more or less inhibited (illustrated by contrast between $A$ and $B$, and $C$ and $D$ in fig. 3 ) and in a highly susceptible species, like barley, the bundles of younger leaves are underdeveloped (fig. 8 ) and may undergo a complete collapse (fig. 7, $B, a$ ).

It is instructive to compare the phloem degeneration in the different leaves

" "Wound gum," "gum," and "gummous material" are used here in a wide sense to indicate the presence of deeply staining products of breakdown of cells. The problematic state of the definition and identification of gum in plants is realized. 
in the same plant. In Avena sativa leaf 1, that is, the oldest leaf, showed only mild phloem symptoms, mainly a dense staining of parenchymatous members of the phloem, although some necrosis was occasionally present (fig. $2, B$ ). Leaf 2 had more severe degeneration than leaf 1 . In addition to the deep staining of cells, necrosis was conspicuous not only in the older but also in the younger parts of the phloem in this leaf (fig. 2, $C$ ). Leaf 3 sometimes showed as pronounced symptoms as leaf 2 , sometimes less pronounced. In leaves 4 and 5 phloem degeneration was commonly encountered in relation to the maturation of the earliest sieve tubes (fig. 2, A). Avena fatua showed a response similar to that of Avena sativa.

Among the Bromus species, B. inermis had mild internal symptoms. In $B$. mollis no symptoms were detected in leaf 1 , but in leaves 2 and 3 phloem degeneration was well expressed. The still younger leaves 4, 5, and 6 exhibited mild to moderately severe phloem degeneration. The $B$. rigidus collection differed from those of the other two species in that it showed dense staining in the phloem of leaf 1 , and that all three subsequent leaves, leaves 2 , 3 , and 4, had severe degeneration. The severity of symptoms in B. rigidus, however, may have depended on the time when the only collection of this species was made, 41 days after the inoculation (table 1 ). The still younger leaves had milder symptoms, with the initial degeneration spatially related to the first mature sieve elements.

In Hordeum hystrix the most pronounced effect upon the phloem was evident in leaves 3 to 5 . Hordeum vulgare showed more severe phloem degeneration than $H$. hystrix. Severe necrosis occurred in leaves 1 to 4 , somewhat milder in leaves 5 and 6 , but even leaf 7 had evident symptoms. In Triticum, leaf 1 was mildly affected, leaves 3 to 5 most severely.

An attempt was made to evaluate the degree of phloem degeneration throughout the plant by assigning numerical values to its expression. On this basis Avena sativa and Hordeum vulgare were judged to be most severely affected. Triticum showed less pronounced degeneration of phloem, although the effect of the disease upon leaf elongation was comparable with that in Hordeum vulgare. According to Oswald and Houston (1953a), yellow dwarf is equally destructive in barley and oat, but among the cereals they found wheat to be most severely damaged when infected in the seedling stage. The present study cannot claim, of course, to give a reliable indication of the degree of susceptibility because relatively few plants of each species were examined and the timing of the collections with reference to the date of the inoculation was somewhat varied in the different species (cf. table 1). The purpose of the study was to examine as much material as possible from single plants in order to follow the developmental course of symptoms.

Phloem degeneration spreads to the axillary buds and here the various effects are comparable with those in the main shoot. Inhibition of leaf elongation, reduction in height of the apical cone, reduction in the plastochronic distance from the apex of the leaf with the first mature vascular elements were recorded in the axillary shoots.

Phloem degeneration is readily observed in the vascular bundles of the axis below the apical meristem (fig. 5). In fact, in the nodal regions of the axis where the leaf traces of leaves of various ages are densely aggregated, 

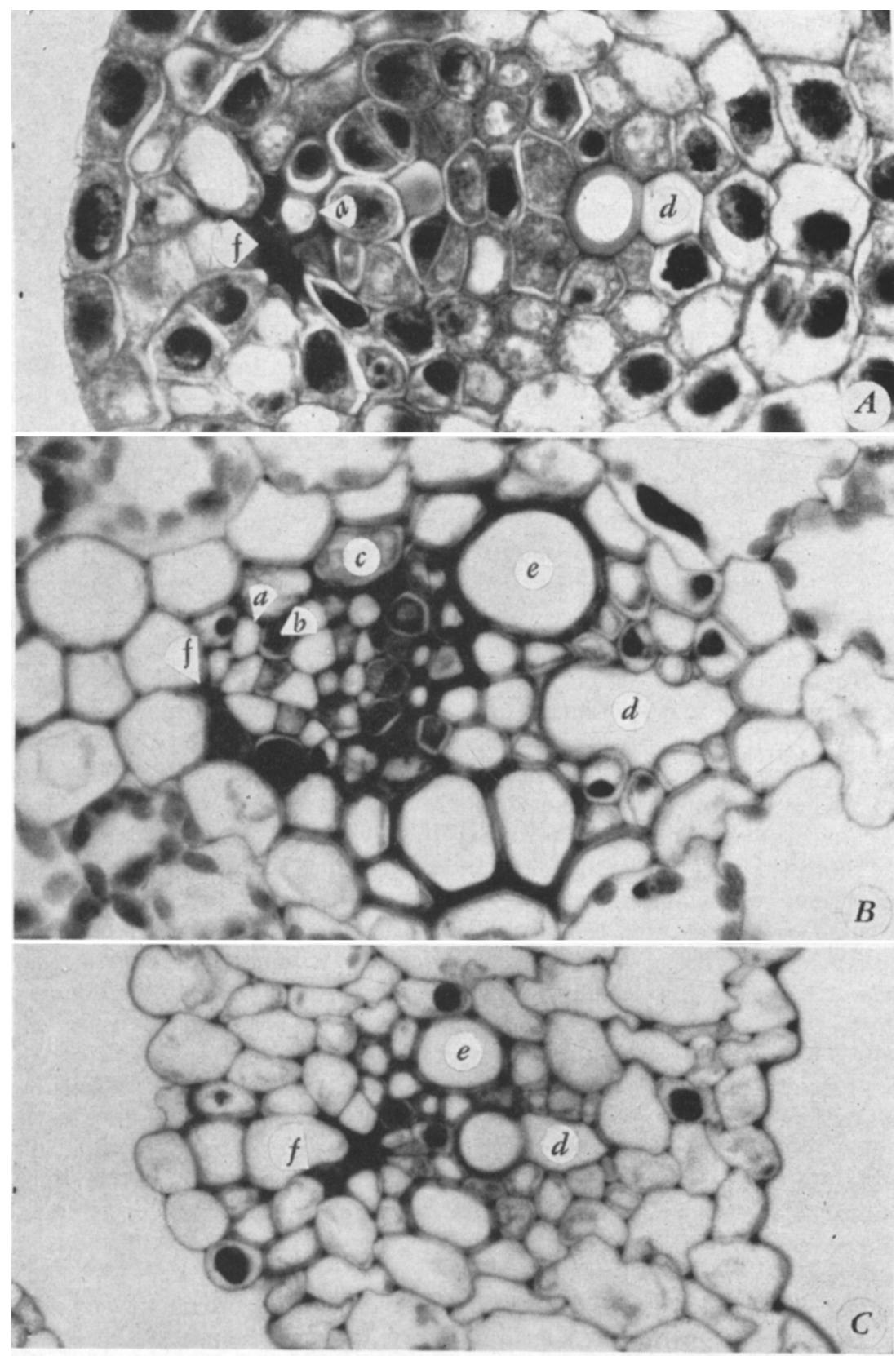

Fig. 2. Avena sativa, oat. Yellow dwarf. (Noninfected Avena in figs. 16, 18, and 19.) Vascular bundles from plants collected 37 days $(A)$ and 23 days $(B, C)$ after planting and 27 days $(A)$ and 13 days $(B, C)$ after inoculation. $A$, from fifth, $B$, from first leaf blade, and $C$ from second leaf sheath. Details are: $a$, sieve element (two are necrotic in $A$ ) ; $b$, companion cell; $c$, parenchyma cell; $d$, earliest xylem (replaced by lacuna in $B$ and $C$ ); $e$, latest xylem element; $f$, necrotic obliteration of cells. (All $\times 850$.) 


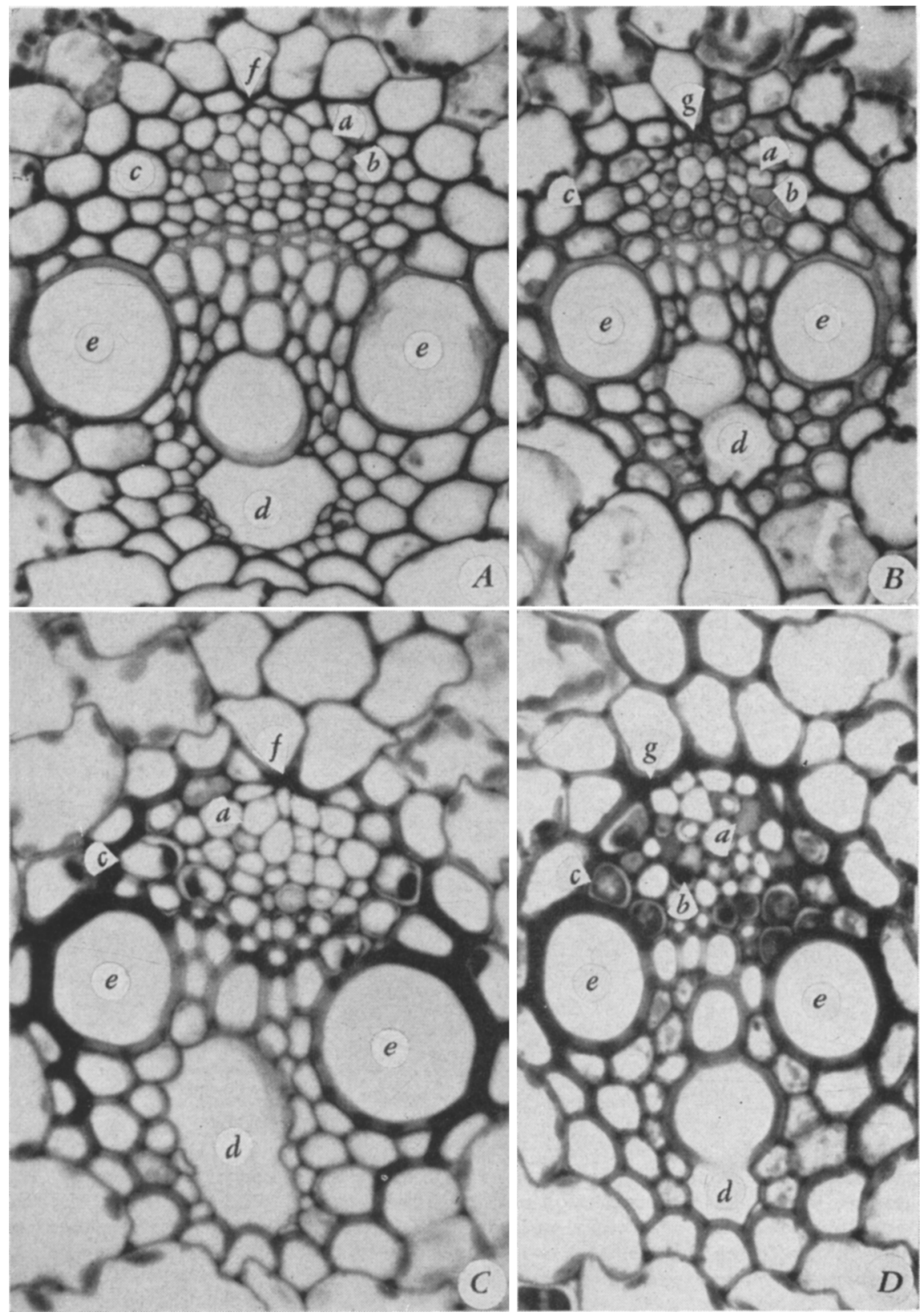

Fig. 3. Hordeum vulgare, barley. Yellow dwarf $(B, D)$ and controls $(A, C)$. Median $(A, B)$ and lateral $(C, D)$ vascular bundles from plants collected 30 days $(A, B)$ and 39 days $(D, C)$ after $B$ and $D$ were inoculated. All bundles are at end of development. Details are: $a$, sieve element (with gum in $D$ ); $b$, companion cell; $c$, parenchyma cell (densely stained in $D)$; $d$, protoxylem lacuna ; $e$, metaxylem element; $f$, normal obliteration of protophloem cells; $g$, necrotic obliteration. $(A, B, \times 800 ; C, D, \times 850$.) 

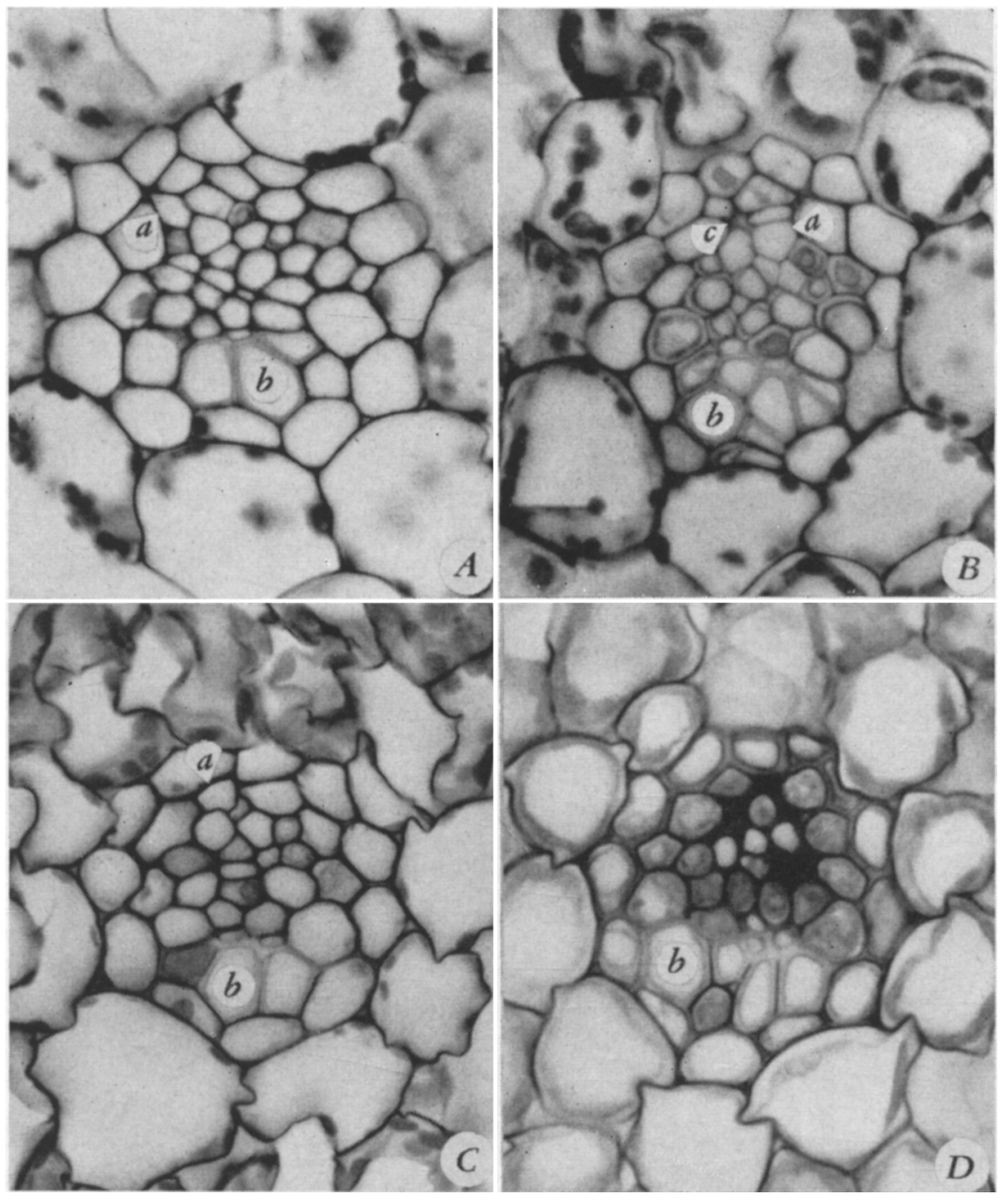

Fig. 4. Hordeum vulgare, barley. Yellow dwarf $(B, D)$ and controls $(A, C)$. Small vascular bundles, $A$ and $B$ from youngest expanded leaves, $C$ and $D$ from somewhat older leaves. $A$ and $B$ from same plants as fig. $3, A$ and $B$, respectively. Plants used for $B$ and $D$ were collected one month after inoculation. All bundles are at end of development. They contain only metaphloem and metaxylem. The normal bundles $(A, C)$, therefore, show no phloem obliteration and no protoxylem lacunae. In contrast, necrotic obliteration occurred in phloem of affected bundles, mild in $B(c)$; severe in $D$. Details are: $a$, sieve element; $b$, xylem element; $c$, necrotic obliteration. (All $\times 800$.) 

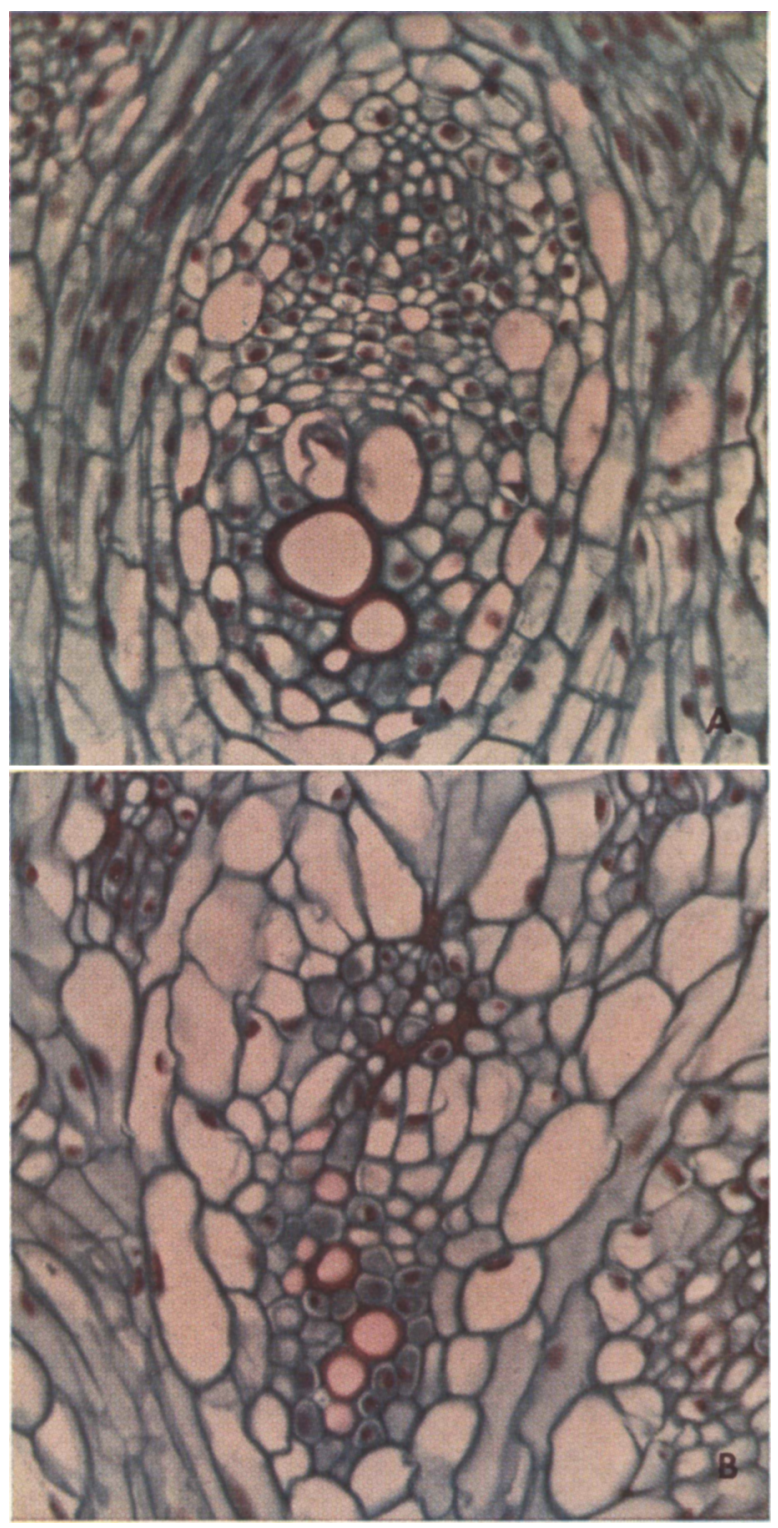

Fig. 5. Hordeum vulgare, barley. Yellow dwarf $(B)$ and control $(A)$. Vascular bundles constituting leaf traces in axes of shoots. The diseased plant $(B)$ was collected 5 weeks after inoculation and 3 weeks after external symptoms appeared. In both photographs the phloem is above, the xylem below. The secondary walls of mature tracheary elements and wound gum in the degenerated phloem in $B$ are stained red. In $A$ protophloem is still intact (group of small cells above in the phloem), metaphloem is partly differentiated. Below metaphloem is immature xylem with four wide vessels, two right and left and two below, still without lignified secondary walls. In $B$ protophloem has undergone necrotic obliteration. Part of metaphloem also has become necrosed and procambial cells below it have enlarged (wound healing reaction). The xylem is underdeveloped, especially in its upper part where procambial cells have enlarged. Details are: staining with safranin and fast green. (Photographed on Ektachrome.) (Both $\times 367$.) 


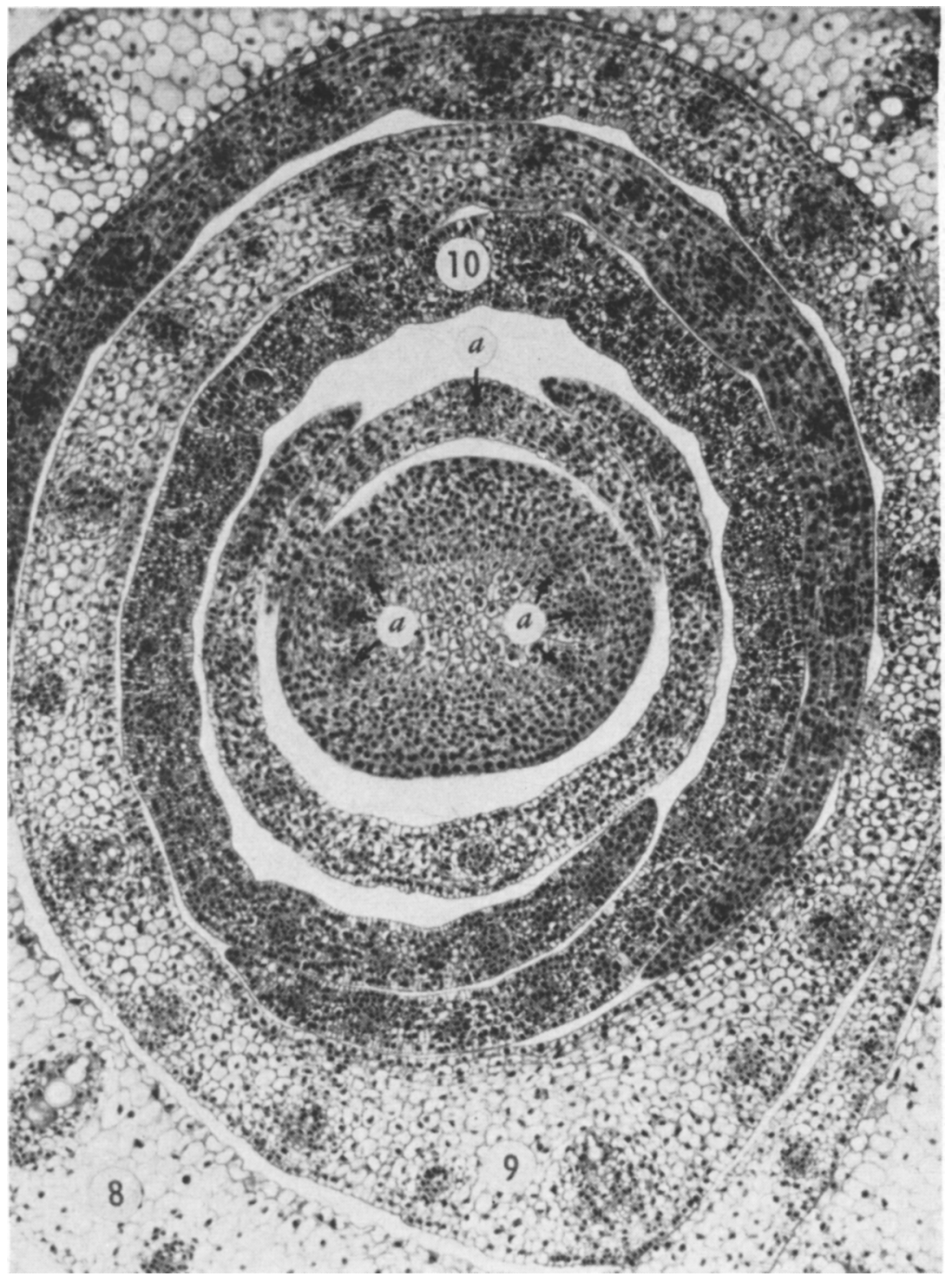

Fig. 6. Hordeum vulgare, barley. Control. Shoot tip, with axis in center and young leaves surrounding it, from a plant collected 52 days after planting. An inflorescence was initiated. The procambial bundles $(a)$ in axis are traces of spikelet primordia. Details are: $a$, procambial bundles; the numbers $8-10$ on leaves indicate the order of these leaves as counted from base of plant upward. $(\times 132$. 

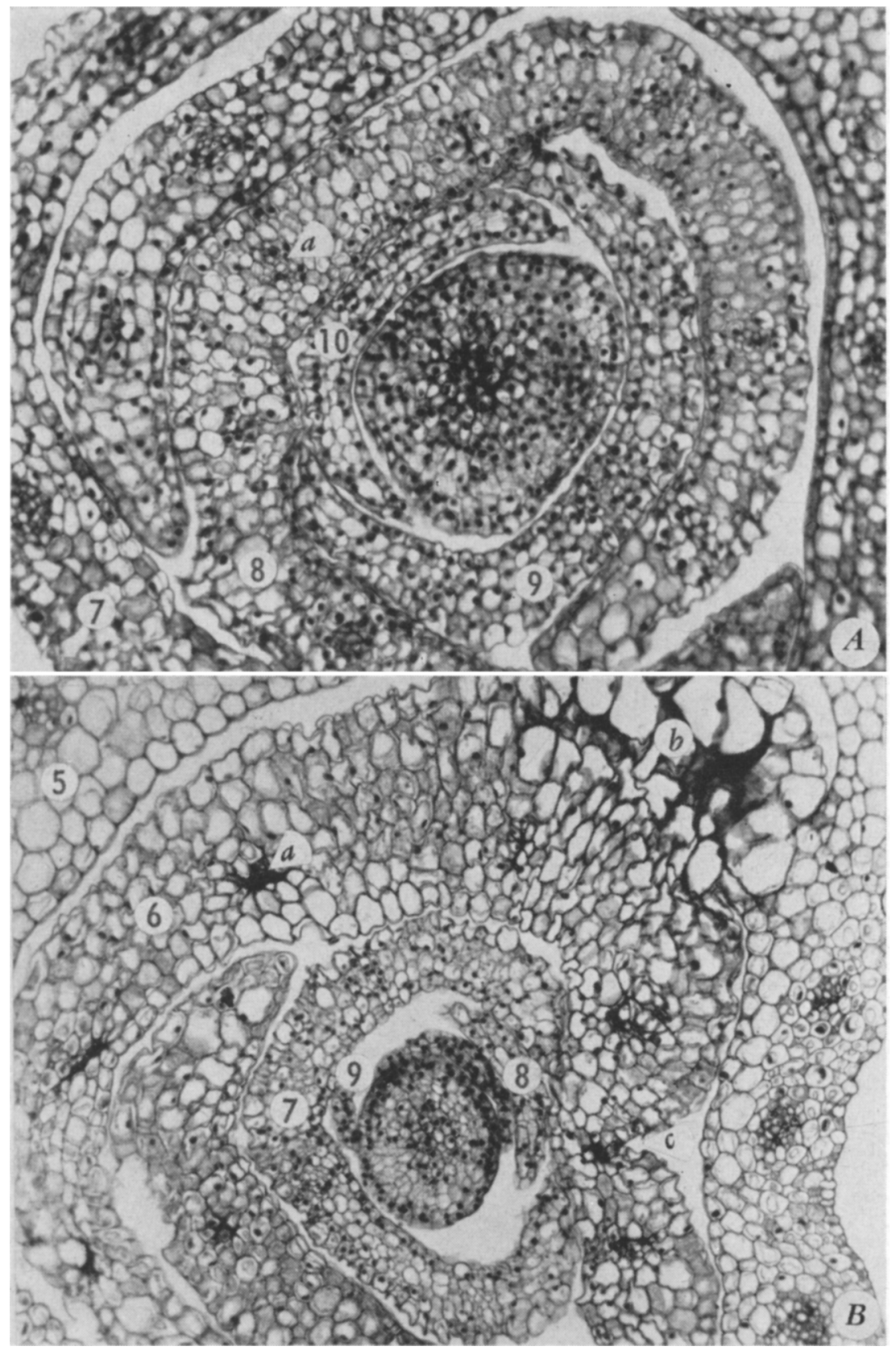

Fig. 7. Hordeum vulgare, barley. Yellow dwarf. Shoot tips; axis in center surrounded by young leaves. Both plants collected 52 days after planting and 39 days after inoculation; $B$ more severely affected than $A$. In contrast to control (fig. 6 ) both shoots were in vegetative stage, showed reduced meristematic activity, and had large and highly vacuolated cells. Leaves show a hypertrophic increase in thickness and are distorted. In $B$ hypertrophy and necrosis at $b$. In $A$ center of axis is necrosed and vascular bundles are underdeveloped. In $B$ severe necrosis in many bundles $(a)$. Details are: $a$, vascular bundle; $b$, hypertrophy and necrosis; $c$, partly collapsed part of leaf ; numbers 7-10 in $A$ and 5-9 in $B$ indicate order of leaves as counted from base of plant upward. $(A, \times 180 ; B, \times 138$. $)$ 


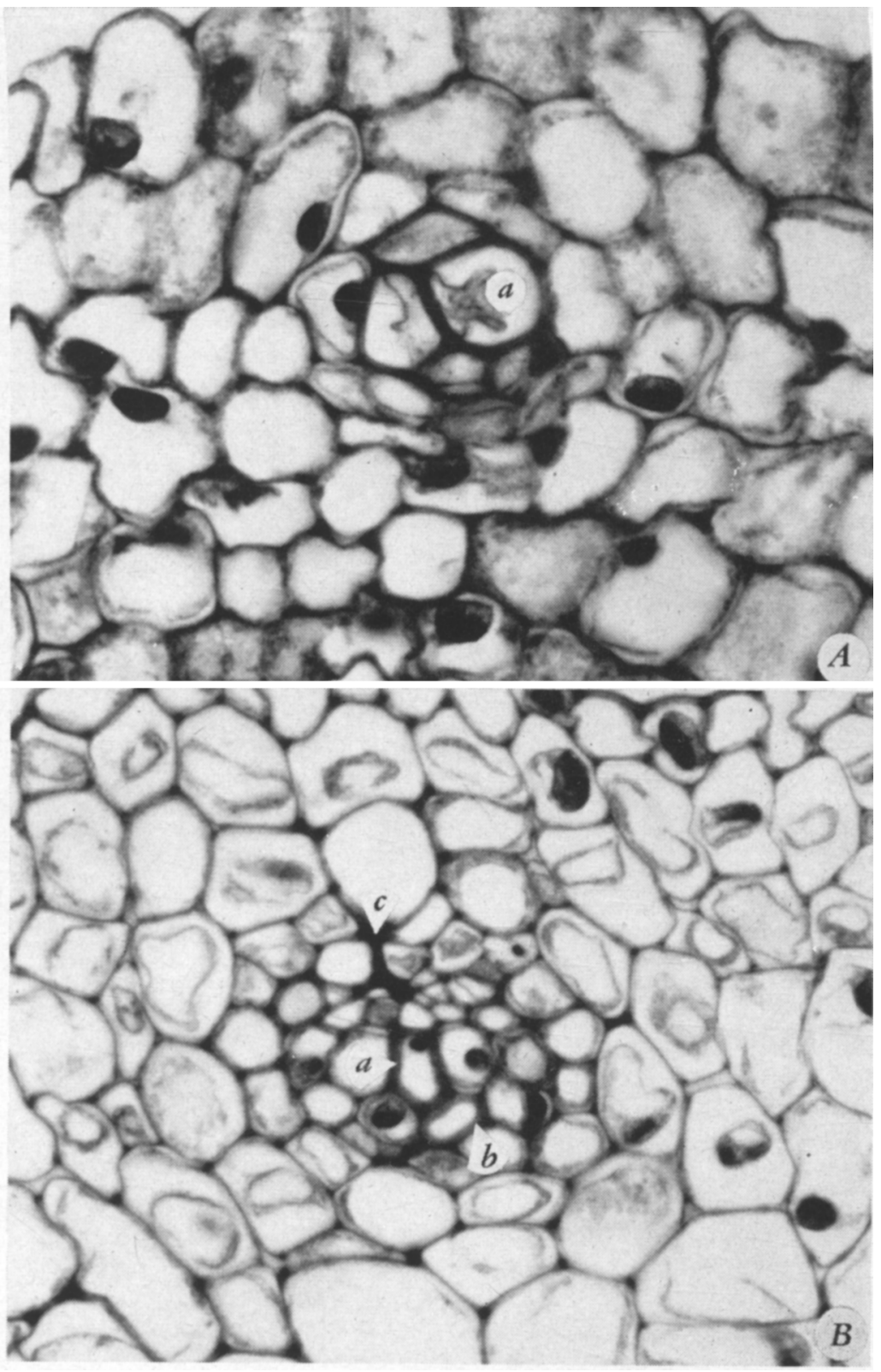

Fig. 8. Hordeum vulgare, barley. Yellow dwarf. Vascular bundles from the severely affected shoots depicted in figure 7. $A$, One of smallest vascular bundles from leaf 7 in figure $7, A$. Three excessively wide sieve elements are at $a$, to left of $a$, and above $a$. No xylem is present. $B$, Lateral bundle from leaf 5 in figure $7, B$. It is underdeveloped, espeeially with regard to the xylem. The earliest phloem has undergone necrotic obliteration (c). At $a$, sieve element in later part of phloem with a thick wall and an extruded nucleolus. Details are: $a$, sieve element; $b$, xylem element; $c$, necrotic obliteration. (Both $\times 850$.) 
a check on the presence of phloem degeneration may be made most readily. It is of interest that this part of the plant was found by Allen (1956) to be particularly satisfactory for studies of staining reactions reportedly identifying the presence of virus in the tissue.

Effect Upon Tissues Other than Phloem. The presence of the yellow dwarf virus induces degenerative changes in various other tissues in addition to those in the phloem. In the material used for the second part of the study the dense staining of parenchyma cells was not restricted to the phloem, but was evident in the xylem also (Esau, 1957a). Gum accumulations were encountered in the xylem of oat and barley, particularly often in vascular bundles in the axis. The Clinton Oat leaves from Illinois also exhibited this phenomenon. In barley a complete collapse of the vascular bundles was observed in young leaves in collections made over one month after the inoculation (fig. $7, B$ ).

As was mentioned earlier, the apical meristem shows a reduced activity expressed, as contrasted with the controls, in a smaller number of leaves initiated on the plant and in the higher position of the youngest leaf with respect to the apical meristem (table 1). Histologically, however, most collections showed no evident abnormalities in the youngest part of the shoot above the region of maturation of the phloem. Sometimes the latest collections exhibited an increased degree of vacuolation of the young shoot parts.

Hordeum vulgare plants, in which the infection was of the longest duration, suffered the most pronounced changes in the youngest part of the shoot, both in the 1951 and in the 1954 collections. While in the normal plant the apical meristem progressed toward the initiation of the inflorescence, and the axis and young foliar organs showed the density of cytoplasm characteristic of the stage (fig. 6)-somewhat more highly vacuolated than in the vegetative stage-the diseased plants remained in the vegetative stage, but in their young shoot parts the cells increased in size above the normal for this level and became conspicuously vacuolated (fig. 7). As a result of the enlargement of cells, the young leaves became thicker than is normal for leaves located at such a short distance from the apical meristem. In some areas the leaf thickness was much exaggerated both in number and in size of cells (fig. 7, $B$, at $b$ ); in other areas the leaf appeared collapsed, perhaps in relation to the collapse of vascular bundles (fig. 7, $B$, at $c$ ).

Despite the early increase in thickness of the leaves in severely affected plants, at maturity they may appear underdeveloped and thinner than the leaves of healthy plants. An absolute increase in thickness may occur, however. The difference in the final result appears to depend on the age of the leaf at the time of infection and the severity of the disease. Figure 7 suggests that mitotic activity may be inhibited and, as a result, the leaves may fail to form the normal number of layers of the mesophyll. Such leaves would be finally thinner than normal (compare leaf 9 in figures 6 and $7, A$ ). On the other hand, a development exhibited by leaf 6 in figure $7, B$-an approximately normal number of cell layers combined with pronounced hypertrophy of cells (at $b$ ) - may lead to an abnormal final thickness of a leaf.

The reduction of meristematic activity and the abnormal enlargement of cells have a distinct effect upon the vascular bundles. The suppression of 
cell division results in underdeveloped bundles, especially with regard to the xylem (fig. 8, $B$ ); and bundles that differentiate at the height of cell enlargement contain abnormally wide sieve elements (fig. 8, $A$ ).

In Avena sativa and Hordeum vulgare necrosis was often encountered in the ground parenchyma outside the vascular tissues. An example of such necrosis in a young leaf is given in figure $7, B$, at $b$. The parenchyma surrounding the vascular bundles in the axis and that of the pith became necrosed and the necrosis was followed by extensive collapse of tissue and

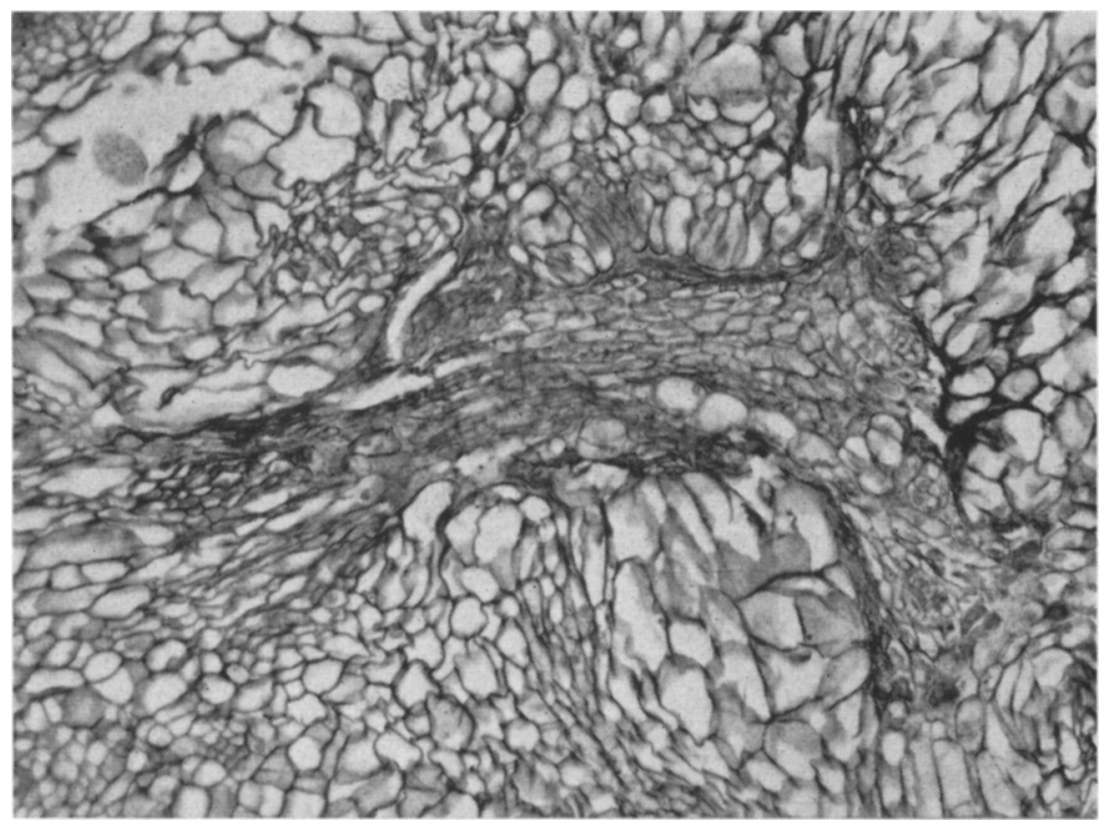

Fig. 9. Hordeum vulgare, barley. Yellow dwarf. Part of young axis of a plant collected 5 weeks after inoculation and 3 weeks after external symptoms appeared. Necrosis and general collapse of cells, accompanied by enlargement of parenchyma cells outside collapsed area, occurred in center of axis. The shoot apex was necrosed in this plant. $(\times 373$. $)$

an enlargement of cells on the periphery of the collapsed area (fig. 9), evidently a wound-healing reaction. The necrosis in the ground parenchyma of the axis was often present close to the apical meristem (fig. 7, $A$ ) and in barley this meristem, too, became necrosed in some plants.

The increase in thickness of young leaves has been referred to in the discussion of figure 7. An increase in thickness occurs in older leaves also. No systematic survey of leaf thickness was carried out, only occasional observations were made, with reference to some leaf deformities, such as puckering, wavy margins, and serrations. In the leaves with wavy margins or with puckered blades the mesophyll thickness was uneven. In figure $10, A, B$, for example, the puckered leaf of Bromus mollis has thicker mesophyll in the right half of the blade (fig. $10, B$ ), a feature particularly clearly discernible in the margin of the leaf. The greater thickness is associated with somewhat larger cells and also with larger intercellular spaces. 
A difference in thickness of leaf margins in an Avena sativa leaf with wavy margins is illustrated in figure $10, C$ : the margin shown to the left is thinner than the one to the right. The difference in cell size is not great but is suggested by the contrast in the diameter of the immature metaxylem elements (arrows). The larger size of the substomatal chamber (cross) in the right margin indicates a larger volume of intercellular space in this part of the leaf. The wider margin is comparable with the margins of healthy leaves in similar stages of development (fig. 10,D). Possibly, in this instance, the difference in thickness between the two margins in the diseased leaf is a result of an underdevelopment of the thinner part of the blade. The searcity of chloroplasts, often combined with a small size of these bodies, is further evidence of an underdevelopment of parts of the blade. On the other hand, the condition in the Bromus mollis leaf shown in figure $10, A, B$, appears to have resulted from hypertrophy of parts of the blade, since the thinner leaf margin (fig. 10, $A$ ) was similar to those in the healthy leaves. Thus, probably, the deformations in the leaves result from both hypertrophy and hypoplasia. The most direct cause of the puckering of blades and of the waviness of margins is the uneven development of the mesophyll and the longitudinal alternations of thick and thin areas along the margin of the leaf.

The serrations in leaves, which are sometimes cut so deeply into the blade that parts of it are severed during growth (Oswald and Houston, 1953a), were found to be associated with localized necrosed areas in the blade. Parts of the leaf margin died off leaving a break in the continuity of the mesophyll. The underdevelopment in parts of the margin mentioned with reference to figure $10, C$, is probably a type of degeneration that in a more severe form leads to a necrosis of the mesophyll.

The material collected for the anatomic study in Davis happened not to show any exudation of sugary liquid that occurs in plants affected with the yellow dwarf. The Clinton Oat leaves from Illinois were specifically collected for the study of material with exudate. In some earlier research (Bennett and Esau, 1936) evidence was presented that the sugary exudate frequently appearing on leaves of sugar beets infected with curly top was derived from the degenerated phloem. Breaks in the ground parenchyma were found leading from the necrosed phloem through the broken epidermis to the surface of the leaf. The leaves of oat infected with the yellow dwarf virus showed no such communication between the phloem and the exterior of the leaf. Although the phloem was severely degenerated and even the bundle-sheath cells were sometimes densely stained, not unlike the parenchyma in the vascular tissues (fig. $11, B$, above $b$ ), no breaks were found in the tissues surrounding the vascular bundles.

On the other hand, the mesophyll cells of the leaves with exudate were in various stages of degeneration, some having undergone a complete necrosis (fig. 11, B). In such leaves, the substomatal chambers were often filled with deeply staining material (fig. 11, C). These observations suggest that the exudate may result from pathologic changes in the mesophyll, that it accumulates in the intercellular spaces, and that it leaves the mesophyll through the stomata. 


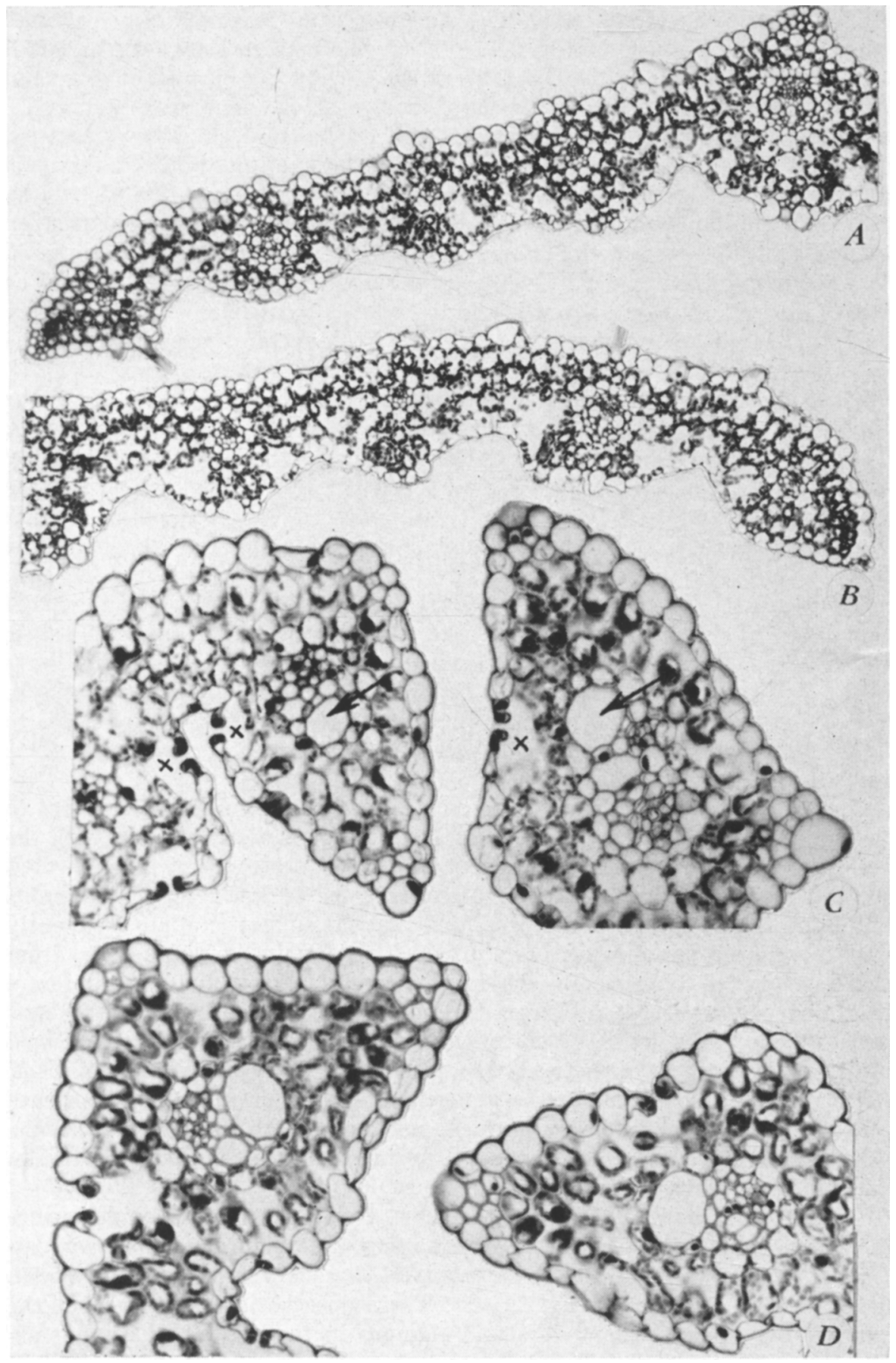


Fig. 10. Hordeum hystrix, Mediterranean barley $(A, B)$ and Avena sativa, oat $(C, D)$. Yellow dwarf $(A-C)$ and control $(D) . A$ and $B$ two halves of a section of fourth leaf of a plant collected 39 days after planting and 26 days after inoculation. The leaf was puckered. The right side of leaf $(B)$ is thicker than left $(A) . C$, Margins of fifth leaf, which was still rolled, and margins were overlapping. The margins are unequal in thickness. From a plant collected 37 days after planting and 27 days after inoculation. $D$, Overlapping margins of sixth leaf on a plant collected 37 days after planting. This control leaf was comparable in size and stage of development to affected leaf in $C$. The two margins are nearly equal in thickness. Details are: arrows, metaxylem elements; crosses, substomatal chambers. ( $A, B, \times 131 ; C, D, \times 260$.) 

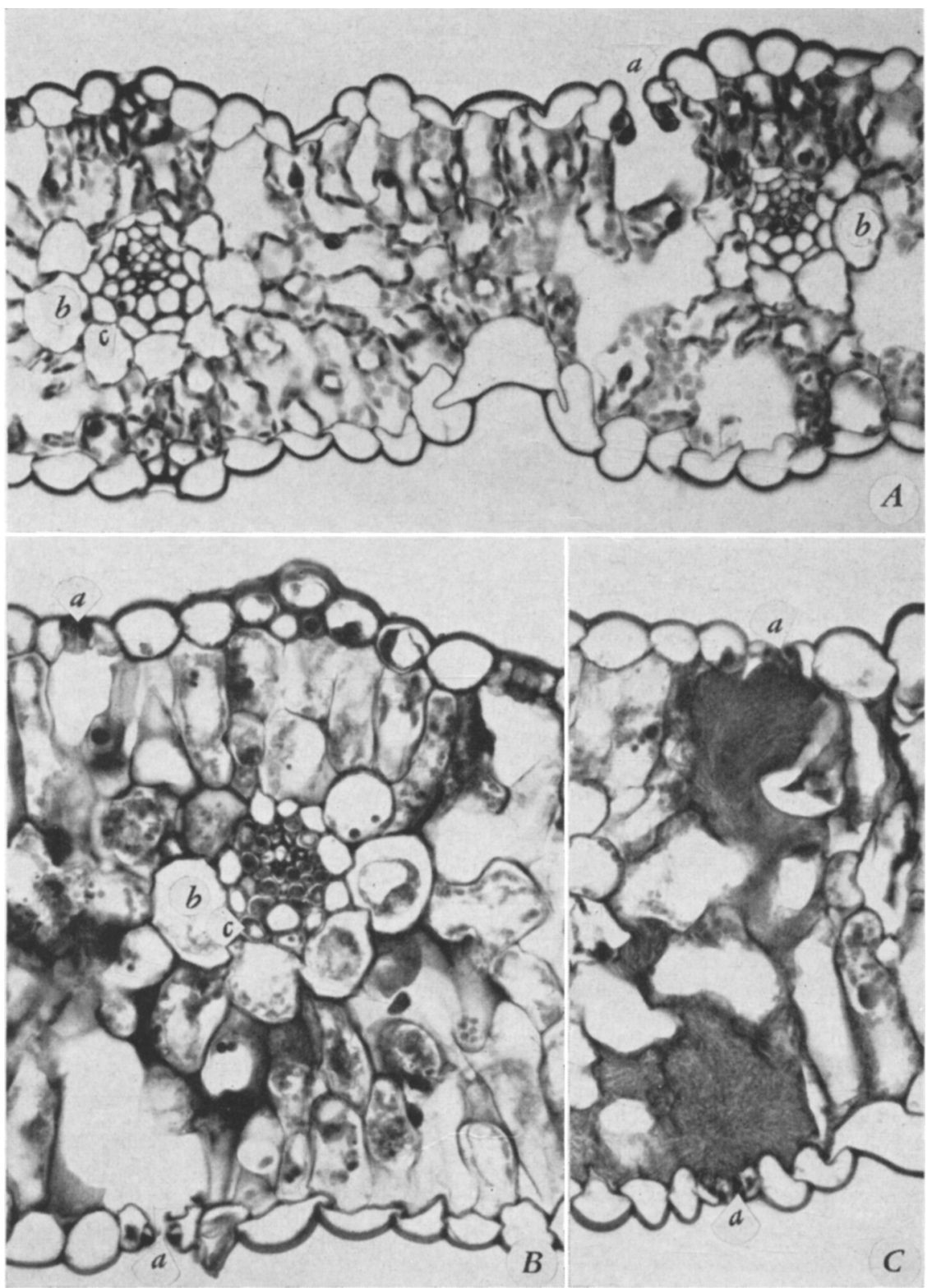

Fig. 11. Avena sativa, Clinton Oat from Illinois. Leaf blades, $A$, control; $B, C$, affected by yellow-dwarf virus. The leaves used for $B$ and $C$ showed a sugary exudate at time of collection. $A$, Mesophyll and two small vascular bundles each with an outer $(b)$ and an inner $(c)$ bundle sheath. Stoma with a substomatal chamber at $a . B$, Mesophyll is thicker than in $A$ (hypertrophy) and its cell contents are disorganized, with the chloroplasts partly or completely degenerated. In vascular bundle intact parenchyma cells of phloem and xylem are deeply stained. There is also necrosis in phloem. $C$, Mesophyll with a deposit in the two substomatal chambers. Details are: $a$, stoma; $b$, outer bundle sheath; $c$, inner bundle sheath. (All $\times 347$. $)$ 
The illustrations of Clinton Oat leaves in figure 11 clearly show the difference in the thickness of the mesophyll between the healthy (fig. 11, A) and diseased material (fig. 11, B, C). Over 100 measurements on eight healthy leaves and on fourteen diseased leaves indicated that the diseased leaf was almost twice as thick as the healthy. The difference obtained was probably slightly exaggerated because the healthy leaves suffered more distortion in preparation than the diseased leaves, but most of the difference is actual. As is clearly evident from figure 11, the difference in thickness is accountable for by the difference in the size of cells, a relation previously pointed out with regard to the leaves of barley (fig. 7).

Figure 11 also shows that the chloroplasts are degenerating in the affected mesophyll. A breakdown of chloroplasts was observed in various species collected in Davis, particularly in relation to the discolorations in leaves ; and, as was mentioned in reference to the uneven development of the mesophyll, deficiencies in chloroplast development also were observed.

\section{EFFECT OF MALEIC HYDRAZIDE UPON THE SHOOT}

External Symptoms. The descriptions of external symptoms that are induced by treatment with maleic hydrazide in various Gramineae (e.g., Currier and Crafts, 1950; Currier et al., 1951; Gifford, 1956 ; Naylor and Davis, 1950) agree with the observations made in the present study. The leaves became first dark green and brittle, later yellow. New growth was retarded. In Hordeum the oldest leaves were retained longer in the treated than in the untreated plants. Droplets of sugary exudate appeared on the leaves of Avena sativa, Bromus rigidus, and Hordeum vulgare. Other investigators observed the exudate in barley (Currier et al., 1951; Gifford, 1956) and in maize (Naylor and Davis, 1950). Currier et al. (1951) and Gifford (1956) also reported localized necrosis of leaf tissues beneath the drops of exudate. A similar phenomenon was noted in the present study.

Growth of the Shoot. The stunting effect of maleic hydrazide was estimated by measurements of leaf blades (table 2). In the youngest leaves, which showed no differentiation into blade and sheath, the part exserted from the older leaf sheaths was measured.

Table 2 shows the retarding effect of maleic hydrazide upon leaf elongation. The effect became noticeable usually beginning with the third leaf. Since mostly only two plants were included in each collection, the figures obtained cannot be used as reliable indices of the relative susceptibility of the various species. One may note, however, that the retardation of growth was particularly strong in Bromus inermis.

The suppression of growth is also clearly shown by the difference between the controls and the treated plants in the number of leaves initiated on the plant (table 2, fourth column). Furthermore, as in the yellow dwarf material, the retardation of growth was associated with an elevation of the morphologic level of maturation of the vascular tissues. The last column in table 2 demonstrates a definite reduction in the plastochronic distance between the apex and the youngest leaf in which the first xylem and phloem became mature (the first sieve element alone usually appears one plastochron 
TABLE 2

EFFECT OF MALEIC HYDRAZIDE UPON CERTAIN DEVELOPMENTAL FEATURES IN THE SHOOT

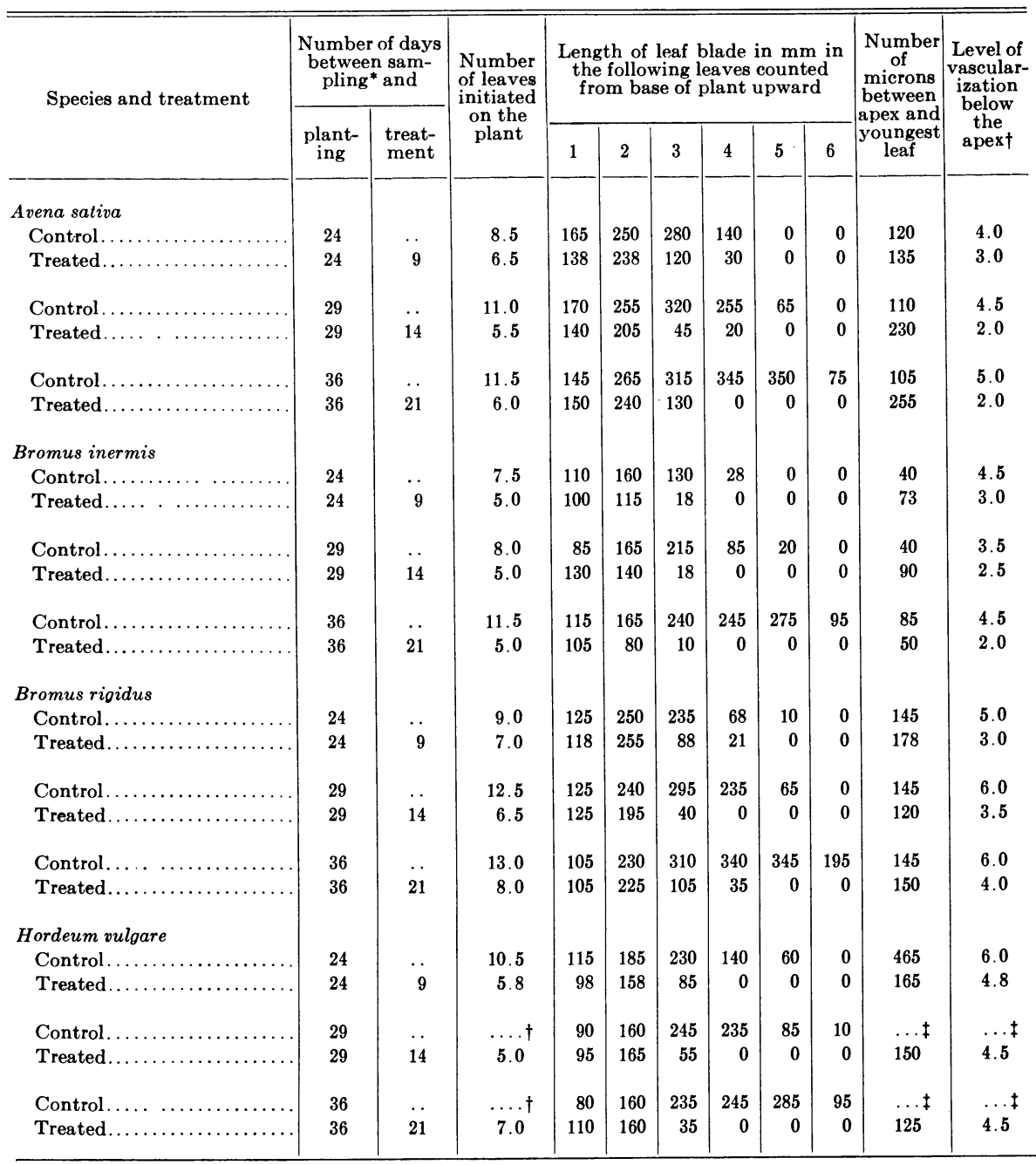

* The first treated collection in each species contained 4 plants, all the others 2 plants each.

+ Expressed as plastochron counted from the apex downward.

$\ddagger$ Inflorescence was initiated.

earlier than the combination of xylem and phloem elements). As in the yellow dwarf studies, the normal barley plants were found to be developing inflorescences before the collections were completed. The treated barley plants remained vegetative.

Maleic hydrazide had a different effect than the yellow dwarf virus upon the height of the apical meristematic cone. In the yellow dwarf material the youngest leaf was consistently closer to the apex than in the controls (table 1, 
second column from the right). In the maleic hydrazide material the situation was variable, the majority of plants showing a higher apical cone in the treated condition (table 2 , second column from the right). A comparison of the shoot apices of treated and untreated plants (fig. 15) suggests that the considerable height of the apical cone in the treated plants results from cell enlargement. In the Hordeum plants used for table 2 the very high apical cone in the first collection of the control was an indication of the transition of the meristem to the formation of the inflorescence (cf. Evans and Grover, 1940; Sharman, 1947). The meristems of the subsequently collected controls were actually those of inflorescences.

The reduction of meristematic activity and the associated phenomena give the sections through the youngest parts of the treated shoots a distinctive appearance. Figures 12 and 13 compare controls with two treated plants of Avena sativa in sections made below the second node from the apex. The control in figure 12, $A$, and the treated shoot in figure $13, A$, were included in the first collection, the control in figure $12, B$, and the shoot in figure $13, B$, in the third collection (cf. table 2). In other words, the shoot in figure $13, B$, was collected later after the treatment than the shoot in figure 13, $A$. The numbers on the leaf sections in the two figures denote the order of appearance of the leaves on the plant, that is, these numbers were obtained by counting the leaves from the base upward. Reference to these numbers serves to complement data entered in the fourth column of table 2 , the number of leaves initiated on the plant. At the time of collection the shoots in figure 12, $A$ and $B$, had initiated nine and eleven leaves, respectively; the shoots in figure 13 , $A$ and $B$, seven and six leaves, respectively. If the leaves are counted from the apex downward, leaves 7 and 9 in figure $12, A$ and $B$, and leaves 5 and 4 in figure $13, A$ and $B$, occupy the same position relative to the apical meristem.

In figure 13 the outermost leaves in both photographs have no discontinuities: the sections passed through the bases of these leaves where the leaves were tubular in structure (lowermost part of the leaf sheath). In figure 12, leaves 4 and 5 in $A$ and leaf 5 in $B$ were cut through their tubular parts. The shortness of the plastochronic distance between the apex and the leaf which is cut through its tubular part in the treated shoots (fig. 13) is associated with the lack of normal extension of internodes and the inhibition of further additions from the apical meristem.

Since the four shoots in figures 12 and 13 are all shown below the node of the second leaf from the apex, the sections may be considered to be of the same plastochronic age if the development of the shoot is studied from the apex downward. Thus viewed, the shoots in figure 13 may be described as having undergone differentiation abnormally close to the apical meristem. The cells in these shoots are larger, the vacuolation of the cells more pronounced, and the cell walls thicker than in the untreated shoots at the same level below the apex. Moreover, the traces of the two youngest leaves visible in the axis in the two shoots in figure 13 have some differentiating and some mature sieve elements, whereas similar traces in the axes in figure 12 consist of procambial cells only. The third leaf from the apex in figure 12 (leaf 7 in $A$ and leaf 9 in $B$ ) also contains only procambial strands. The third leaf from the apex in figure 13, $A$, (leaf 5 ) has mature phloem and xylem elements in 
the median and the large lateral vascular bundles; in fact, the median bundle has no procambial cells left. In the third leaf from the apex in figure $13, B$, the phloem is collapsed and the xylem underdeveloped.

The comparison just made complements the data given in the last column in table 2. In the control in figure 12, B, (cf. third collection of Avena in table 2) the first sieve elements appeared in the fourth plastochron from above (leaf 8 at $a$ ), xylem and phloem in the fifth plastochron (leaf 7 in fig. $12, B)$. In the shoots in figure 13 mature xylem and phloem were present in the third plastochron in $A$ (leaf 5 ), in the second plastochron in $B$ (leaf 5 , shown in figure 14).

Since the treated plants and their controls in each collection were approximately the same age, a comparison of levels at the same plastochronic distance from the apical meristem does not give a proper indication of the relative rate of maturation of tissues in the two kinds of plants. Leaves of the same plastochron as counted from the base of the plant upward should be compared, as was done by Gifford (1956). An examination of the fifth and sixth leaves in Gifford's figures 2 and 3 (the fifth leaf below the sixth is labelled) clearly shows that there is a precocious maturation in the treated plant with reference to the vacuolation and enlargement of ground-parenchyma cells, as well as the differentiation of vascular tissues. In the present paper a comparison of figures 12,13 , and 14 confirms this observation. Leaf 5 in figure $13, A$, appears more mature than leaf 5 in figure $12, A$. At the same time these figures also show that the precocious differentiation in the treated plants is associated with a final underdevelopment. Thus, leaf 4 in figure 13, $A$, did not attain the same thickness as leaf 4 in its control (fig. 12, $A$ ). Similarly, leaf 6 in figure 14 is thinner than leaf 6 in its control (fig. 12, B). At equal plastochronic distances from the apex the axis in a treated plant appears thicker than in the untreated (cf. figs. 12 and 13). If, however, equivalent levels of the plants - as determined by counts of leaves from the base up-are compared, the axis in the untreated plant is thicker than in the treated.

The precociousness of maturation in plants treated with maleic hydrazide is intimately associated with the cessation of meristematic activity. While the meristem in the untreated plants continues to form new increments of the shoot, that of the treated plant undergoes changes characteristic of the process of maturation of ground tissues (fig. 15). Similarly, the leaves begin to mature before they complete their growth by cell division. As a result the leaves are underdeveloped when their growth by cell enlargement is completed. The degree of this underdevelopment depends on the age of the leaf that comes under the effect of the chemical.

Maleic hydrazide may possibly induce cell enlargement in leaves in which the mitotic activity has been completed normally; and if the cells enlarge abnormally in a leaf having the same complement of cells as an untreated, an abnormal increase in thickness would result. Such growth phenomenon was apparently responsible for the increase in thickness and in area of cotton leaves studied by McIlrath (1950). In the present study an increase in thickness of older leaves by cell enlargement was observed in the yellow dwarf material, but not in that treated with maleic hydrazide. The matter was not studied fully, however. 


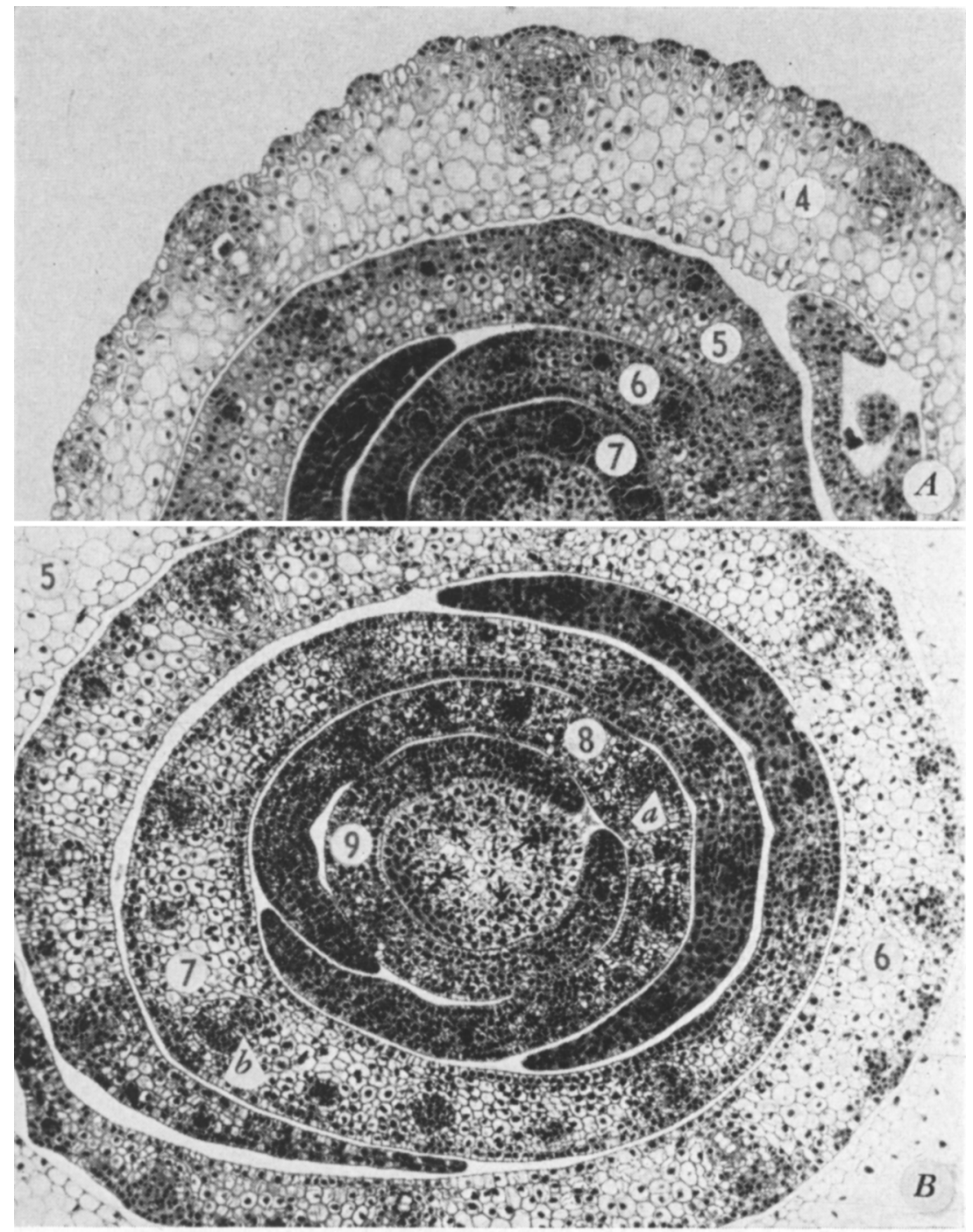

Fig. 12. Avena sativa, oat. Control. Shoots below node of second leaf from apex (leaf 8 in $A$, leaf 10 in $B$ ). The plants were collected 24 days $(A)$ and 36 days $(B)$ after planting. In $A$ leaves 7-9 had no mature vascular elements. Leaf 6 (fourth from the apex) had first phloem and xylem elements. An axillary shoot appears at right between leaves 4 and 5. In $B$, leaves $9-11$ had no mature vascular elements. Leaf 8 (fourth from apex) had first sieve element in median bundle $(a)$; leaf 7 (fifth from apex) first xylem element in median bundle $(b)$. The axis had a conspicuously vacuolated central region and a eumeristematic peripheral region with procambial strands (arrows), the traces of leaves 10 and 11. Details are: $a$, bundle with first sieve element; $b$, bundle with first xylem element; arrows, procambial strands in axis; numbers 4-7 in $A$ and 5-9 in $B$ indicate order of leaves as counted from base of plant upward. $(\times 97$. 

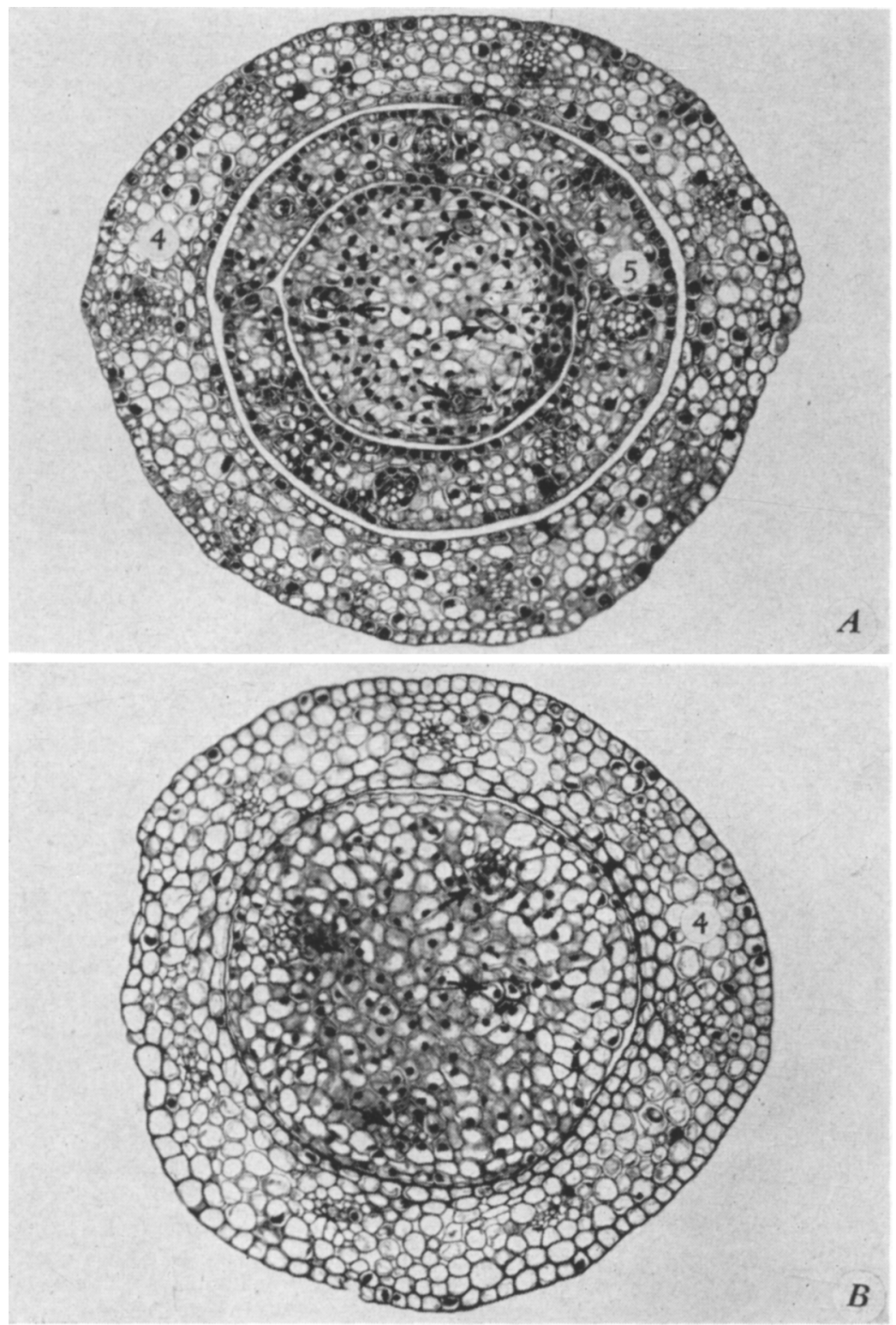

Fig. 13. Avena sativa, oat. Maleic hydrazide. (Controls in fig. 12.) Shoots below node of second leaf from apex. This leaf is sixth on plant in $A$, fifth in $B$. Leaves 5 and 6 of $B$ are shown in figure 14. The plant in $A$ was collected 24 days after planting, 9 days after treatment; in $B, 36$ days after planting, 21 days after treatment. In both meristematic activity was suppressed but cells continued to enlarge and to differentiate. Mature phloem and xylem elements appear closer to apex than in control. In $A$ and $B$ leaf traces of two youngest leaves are visible in axis (arrows). They have differentiated phloem. In $A$ leaves 5 and 4 (third and fourth, respectively, from apex) have phloem in all bundles, and xylem in median and other large bundles. In $B$ leaf 4 (third from apex) shows necrotic obliteration in phloem of all bundles. Numbers on leaves indicate order of leaves as counted from base of plant upward. (Both $\times 97$.) 
Phloem Degeneration. The degenerative changes in the phloem of plants treated with maleic hydrazide are more or less profound depending on the stage of development at which the leaf is affected. In leaves that are relatively advanced in their development at the time of treatment the vascular bundles have a normal complement of cells but the phloem shows abnormalities. The first obvious change is an increase in the density of cytoplasmic staining in the parenchymatous members of the phloem, the parenchyma and the com-

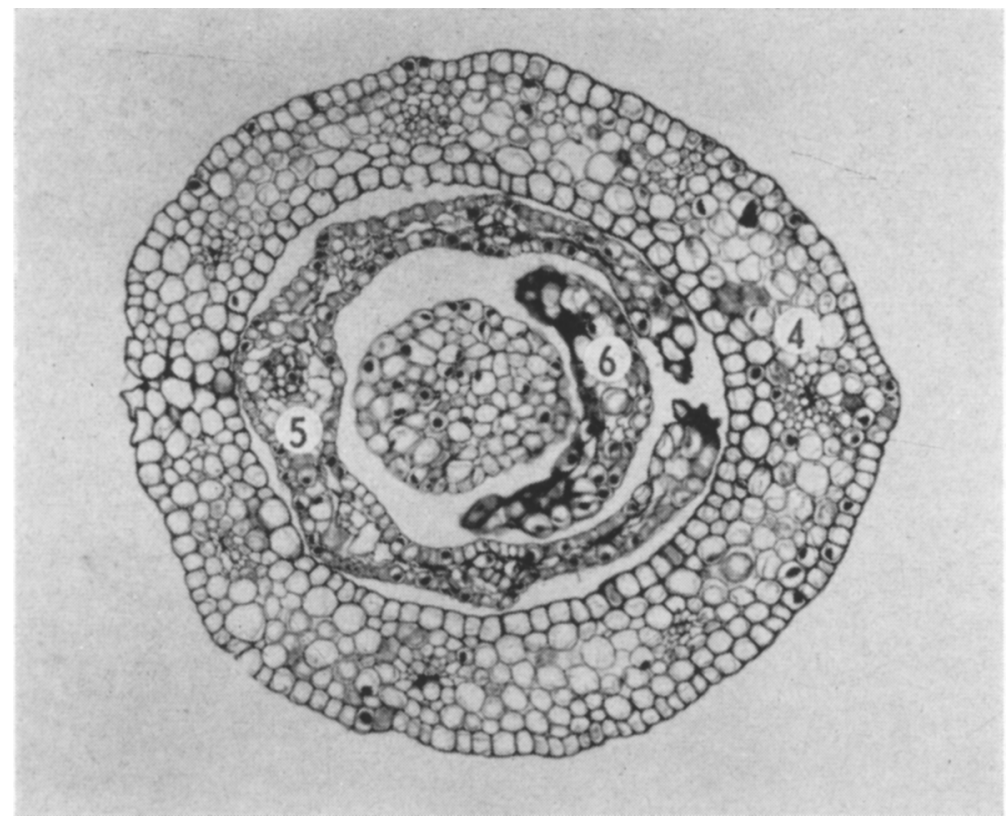

Fig. 14. Avena sativa, oat. Maleic hydrazide. Section from same shoot as in figure $13, B$. This section was taken above node of youngest leaf (leaf 6), 160 microns below apex. At this level leaf 6 has no vascular elements, leaf 5 has three vascular bundles. Necrosis of mesophyll and epidermis has occurred in leaves 5 and 6. Details are: numbers 4-6 indicate order of leaves as counted from base of plant upward. $(\times 97$.

panion cells (fig. 16). The density of staining is often present in the parenchyma of the xylem also (fig. 16, B). A more advanced change is that of necrosis of individual cells, their obliteration, and appearance of gum in the sieve elements (fig. 17, $A$ ). The collapse of necrosed cells becomes more pronounced in time, particularly in leaves that are somewhat younger at the time of treatment (fig. 17, $B$ ).

The abnormalities just described are remarkably similar to those observed in the older leaves of plants infected with the yellow dwarf disease (cf. fig. 2, $B, C$; fig. $3, D$ ). If, however, one compares the phloem that began to differentiate after the inoculation with the virus with that developing after the treatment with maleic hydrazide, differences may be noted. Whereas in the yellow dwarf plants the first sieve elements commonly show no abnormalities until necrosis occurs in spatial relation to these sieve elements (fig. 2, $A$ ), in 


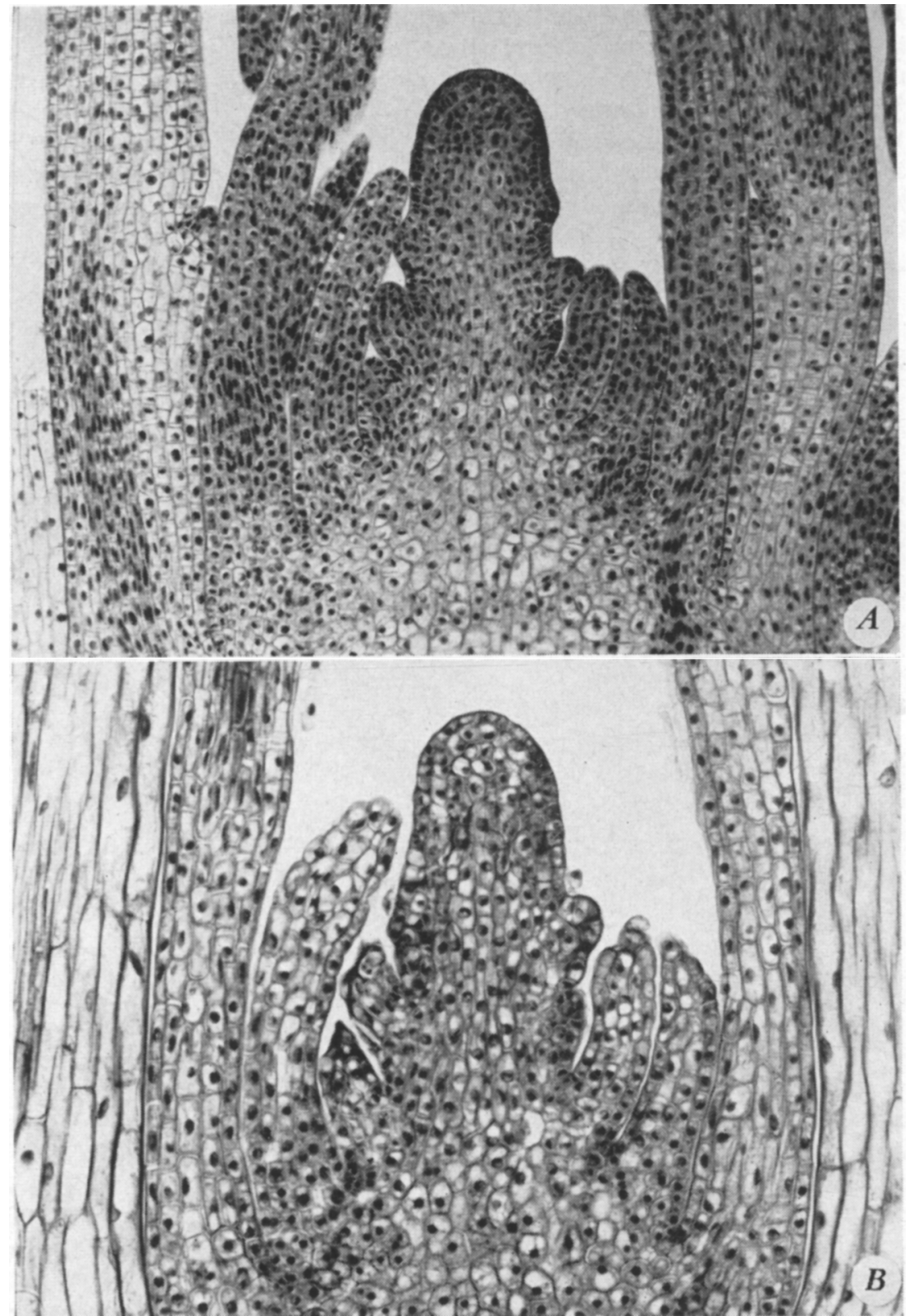

Fig. 15. Hordeum vulgare, barley. Maleic hydrazide $(B)$ and control $(A)$. Shoot tips with leaves in various stages of development in longitudinal sections. The shoot in $B$ was collected 10 days after treatment. The abnormal enlargement and vacuolation of cells in youngest shoot parts indicate cessation of meristematic activity. The difference between treated and untreated shoot in cell size and vacuolation is visible in leaves of all ages in this view. The youngest leaves show some necrosis in $B$. (Both $\times 153$.) 
plants treated with maleic hydrazide the phloem shows a more or less abnormal development from the beginning and no localized necrosis is associated with the first sieve elements.

Figures 18 and 19 illustrate the development of abnormal phloem in plants treated with maleic hydrazide. Not only the phloem but the entire vascular bundle develops abnormally. Figure $18, B$, shows a procambial bundle with one mature sieve element $(a)$ and one immature (below $a$ ). The cells immediately surrounding the sieve elements are part of the procambium. Only one cell layer separates the procambium from the protoderm above and below. All cells are abnormally large as compared with those in a normal leaf in a similar stage of development (fig. 18, $A$ ) and are deficient in number. The leaf in figure $18, B$, was affected by maleic hydrazide before the normal cell divisions were completed. The cells enlarged in the absence of further divisions and, as a result, the sieve elements became abnormally wide. Similar wide sieve elements are discernible in the axes of the two shoots depicted in figure 13. Whether or not these sieve elements have normal sieve areas has not been investigated. They show thick nacreous walls, thicker than normal, prominent pits (or possibly sieve areas) in the lateral walls, are enucleate, and frequently contain extruded nucleoli (such are shown in the later developing phloem in figure $18, D$ ). Chains of these wide short sieve elements may be followed from the leaf into the axis, but sometimes they are interrupted a short distance below the leaf insertion. With further degeneration of the leaves the sieve elements undergo necrosis. Probably in such severely affected leaves no xylem develops.

If the affected leaf is slightly older at the time of treatment, it consists of more cells, the cells are somewhat smaller, the vascular bundles are larger and contain xylem and phloem (fig. 18,D). The first sieve elements in such bundles are of nearly normal width (compare $C$ and $D$ in figure 18) but the subsequent sieve elements are conspicuously wider since they differentiate during the stage of cell enlargement in the leaf. They develop very thick nacreous walls and lack companion cells. In normal phloem the later formed sieve elements (metaphloem) have companion cells.

$D$, contrasted with $C$, in figure 18 clearly shows that meristematic activity had ceased in the bundle in the treated leaf, whereas in the untreated one an active vascular meristem was present between the phloem and the xylem. Another notable difference is that in the affected bundle the number of sieve elements appears excessive in comparison with that of the xylem elements. At the stage of two xylem elements in the normal bundle-as seen in a cross section-only a few protophloem elements are mature (fig. 18, $C$ ).

In leaves that are still older at the time of treatment the abnormal cell enlargement is still less pronounced and involves only the latest sieve elements (fig. 19, B). The most striking feature is again the lack of meristematic activity and the relative underdevelopment of the xylem (contrast $A$ and $B$ in figure 19). Sieve elements (fig. 19, $B, a$ ) often differentiate in contact with the xylem elements (fig. 19, $B, e$ ).

The abnormal development of the phloem in plants treated with maleic hydrazide is obviously related to the changed development of the youngest shoot parts - the cessation of meristematic activity and abnormal enlarge- 


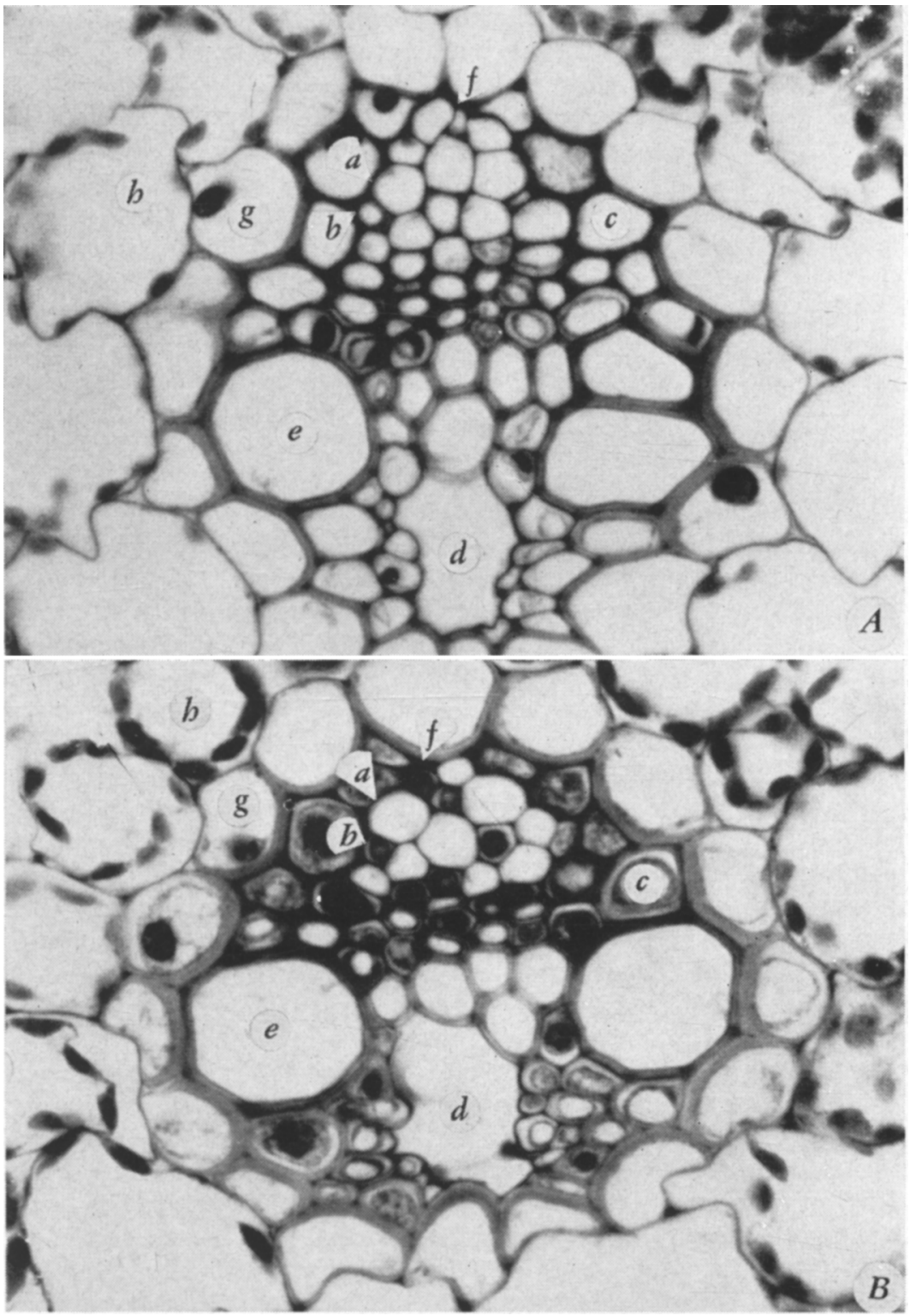

Fig. 16. Avena sativa, oat. Maleic hydrazide $(B)$ and control $(A)$. Median vascular bundles from first leaf. The plants were collected 24 days $(A)$ and 29 days $(B)$ after planting and 14 days after treatment $(B)$. The bundles are at end of development. The protoxylem has been replaced by a lacuna $(d)$. Metaxylem is at $e$ level. The protophloem has been crushed at $f$. The metaphloem contains sieve elements $(a)$ and companion cells $(b)$ and is surrounded by parenchyma cells $(c)$. In contrast to the control $(A)$, the treated bundle $(B)$ shows densely stained companion cells in phloem and parenchyma cells in phloem and xylem. Details are: $a$, sieve element; $b$, companion cell; $c$, parenchyma cell; $d$, protoxylem lacuna; $e$, metaxylem element; $f$, obliterated protophloem; $g$, inner bundle sheath (endodermoid sheath); $h$, outer bundle sheath. (Both $\times 850$.) 


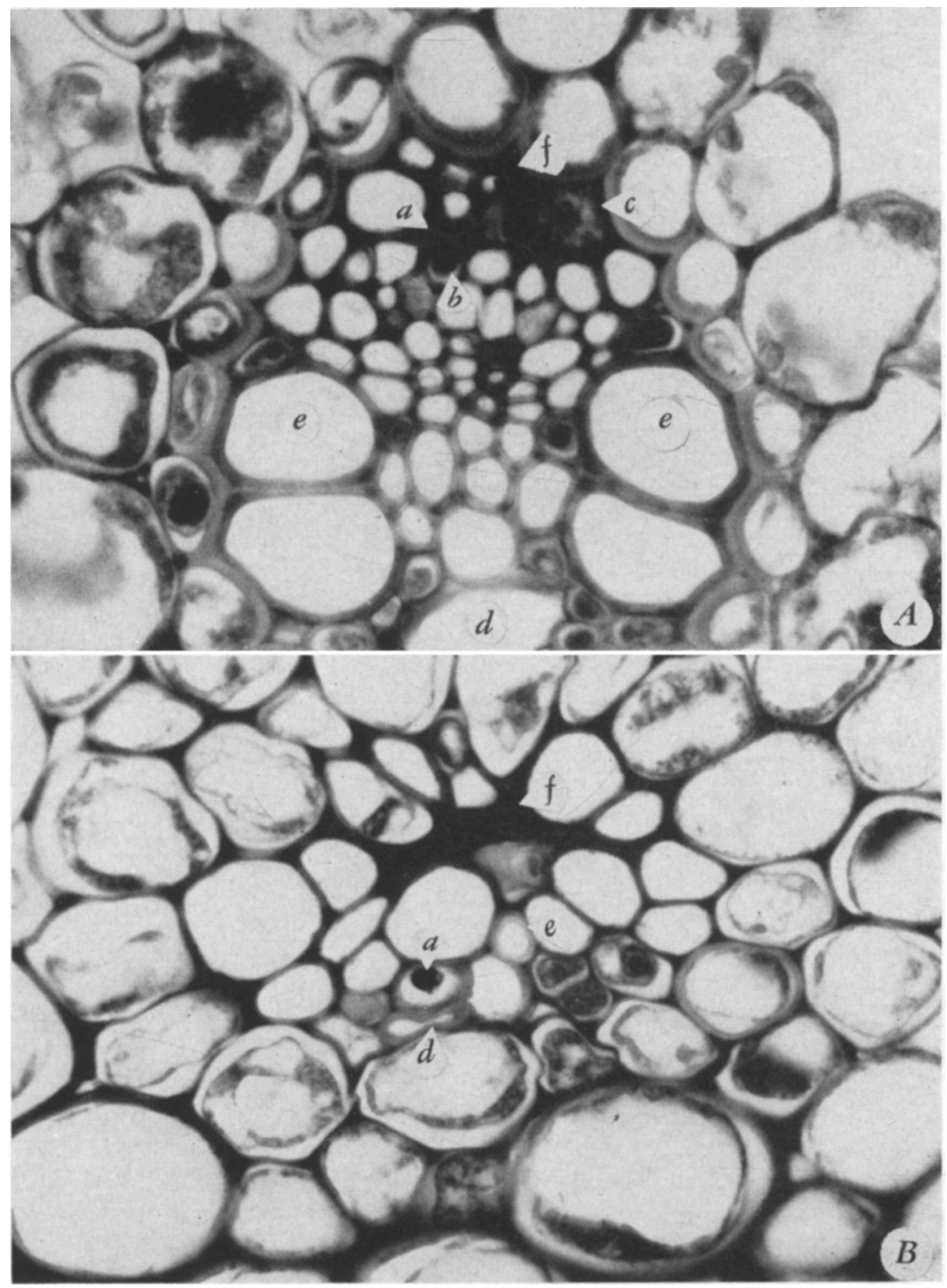

Fig. 17. Avena sativa, oat. Maleic hydrazide. Vascular bundles from leaves of plants collected 36 days after planting and 21 days after treatment. $A$, Bundle from third leaf. Some sieve elements $(a)$ are filled with gum, some companion cells $(b)$ and parenchyma cells $(c)$ are densely stained, and necrotic obliteration has occurred in oldest part of phloem $(f) . B$, Bundle from sheath of fourth leaf. This leaf was affected earlier in its development than leaf used for $A$. The phloem shows severe necrotic obliteration $(f)$ and xylem is underdeveloped. The phloem occupies largest part of the bundle. At $a$ an immature sieve element appears next to a xylem element $(d)$ which is partly crushed. Details are: $a$, sieve element with gum; $b$, companion cell; $c$, parenchyma cell; $d$, earliest xylem element (lacuna in $A$ ); $e$, latest xylem element; $f$, necrotic obliteration. (Both $\times 850$.) 


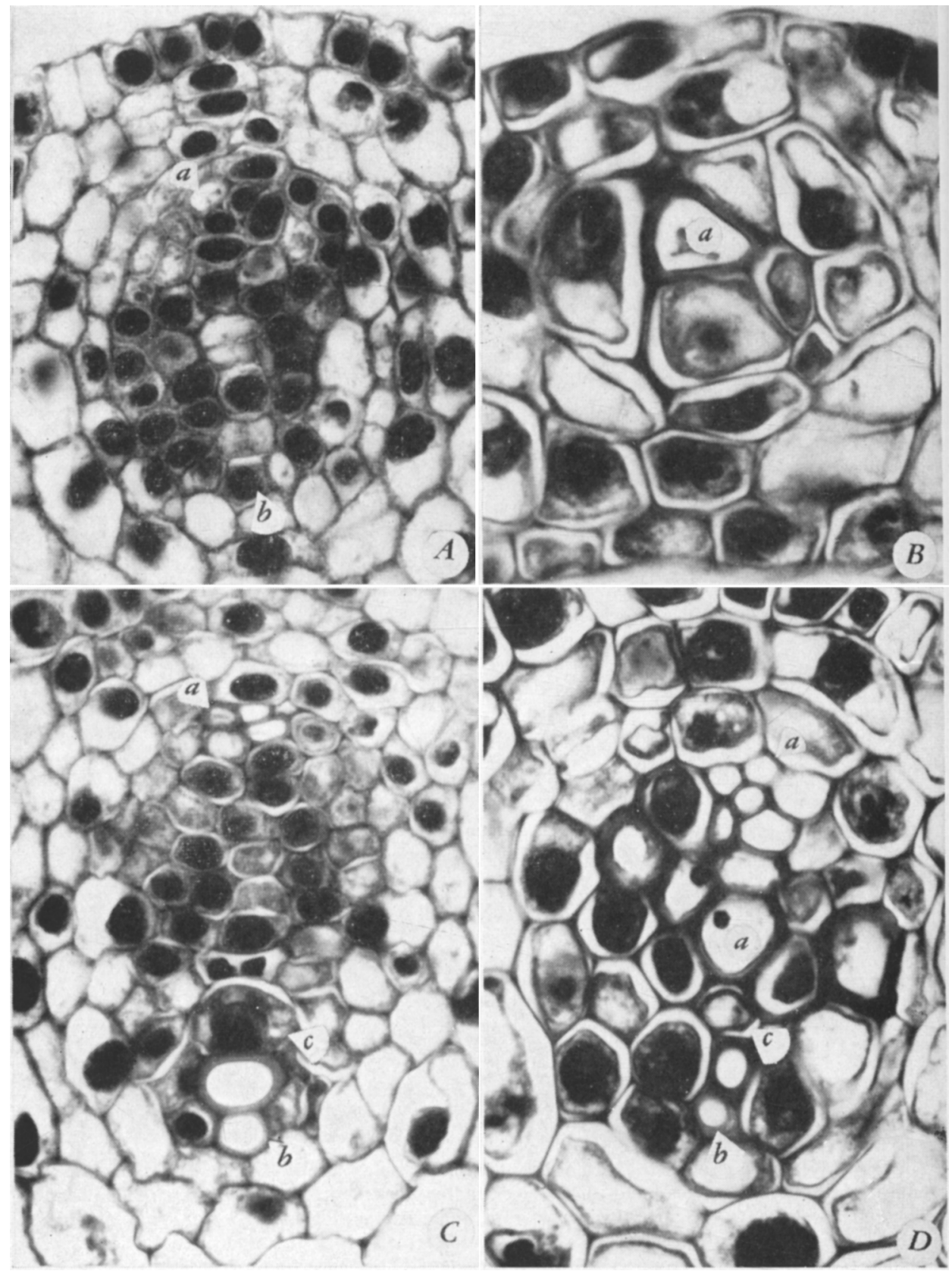

Fig. 18. Avena sativa, oat. Maleic hydrazide $(B, D)$ and control $(A, C) . A$ and $C$, Lateral vascular bundles of leaves 7 and 6 , respectively, on shoot in fig. $12, B . B$ and $D$, Median bundles of leaves 6 (second from apex) and 5 (third from apex), from a shoot comparable to that in fig. $13, A$. In $A$, one mature sieve element $(a)$. In $B$, one mature $(a)$, and one immature (below $a$ ) sieve element. In $C$, five sieve elements $(a)$ and two xylem elements $(b)$. In $D$, two mature xylem elements $(b)$ and many sieve elements $(a)$. The later sieve elements are abnormally wide and have thick walls ( $a$, below). Details are: $a$, sieve element; $b$, earliest xylem element (immature in $A$ ); $c$, latest immature xylem element. (All $\times 850$.) 


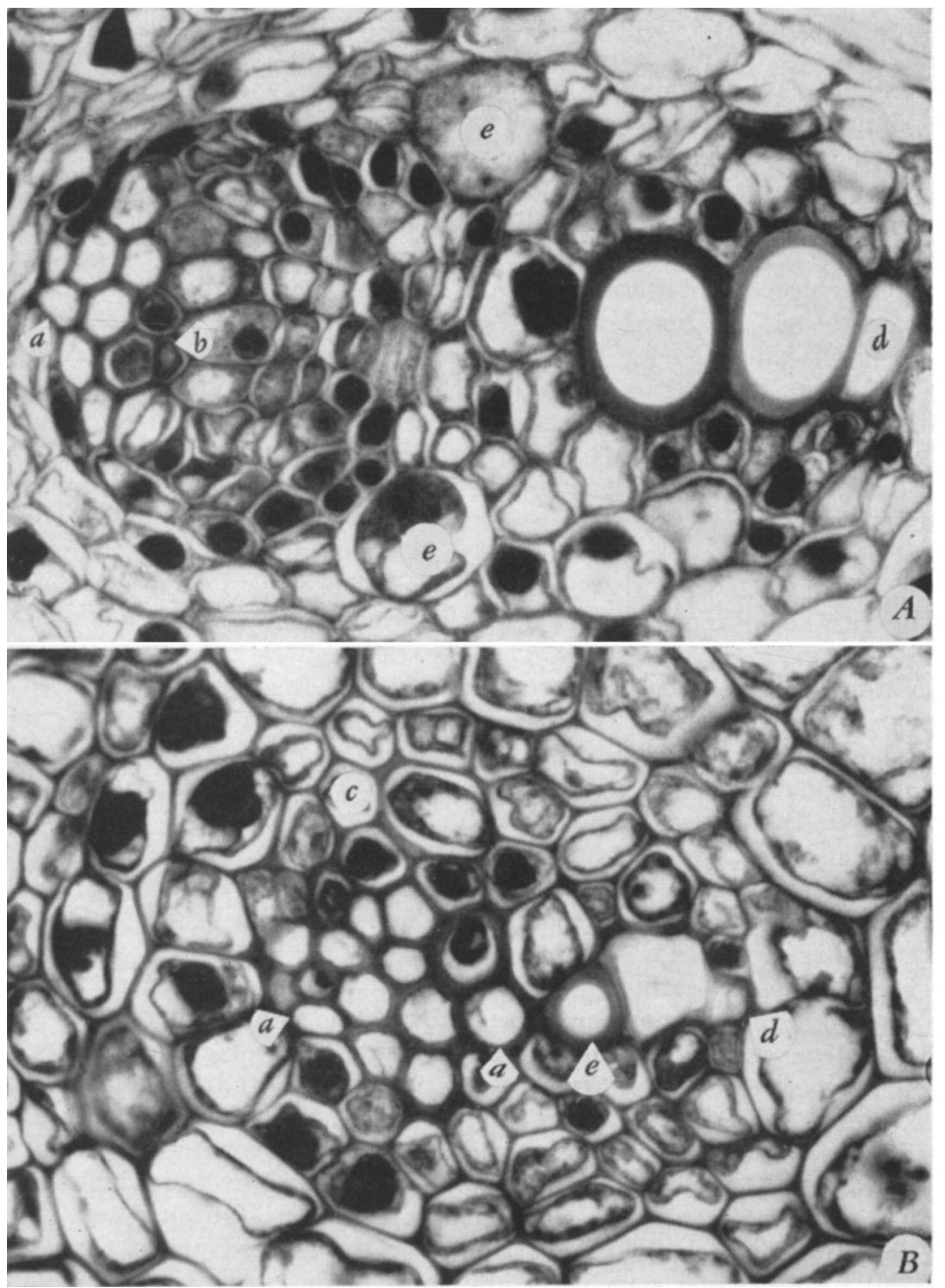

Fig. 19. Avena sativa, oat. Maleic hydrazide $(B)$ and control $(A) . A$, Lateral vascular bundle from sheath of leaf 5 of shoot depicted in fig. 12, $B$. Several protophloem sieve elements $(a)$, without companion cells, are mature. Metaphloem sieve elements, with companion cells $(b)$, are being formed. Of the three mature xylem elements the first $(d)$ is somewhat stretched. The latest metaxylem elements are differentiating at $e$. $B$, Median vascular bundle from leaf 4 (fourth from the apex also) of shoot used for fig. 18, $B$ and $D$. The earliest xylem elements $(d)$ are stretched; the latest is intact $(e)$. Numerous sieve elements $(a)$ have been formed; one ( $a$, to the right) is in contact with the latest xylem element. Details are: $a$, sieve element; $b$, companion cell; $c$, parenchyma cell; $d$, earliest xylem element; $e$, latest xylem element (immature in $A)$. (Both $\times 850$.) 
ment of cells. This development cannot be regarded as a specific effect of the chemical upon the phloem. A similarly changed pattern of development of the vascular bundles may be observed in the yellow dwarf material when the plants are particularly severely affected. In shoots like those depicted in figure 7, in which an inhibition of meristematic activity and abnormal cell enlargement are observed, sieve elements may be unusually wide (fig. 8, $A$ ), the vascular bundles may be underdeveloped, with the sieve elements differentiating next to the xylem elements (fig. 8, $B$ ). However, the occurrence of an early necrotic obliteration (fig. $8, B$ ) characterizes the phloem development in the yellow dwarf material, but not in that in plants treated with maleic hydrazide (fig. 19, $B$ ). Later, the abnormally developed phloem in maleic hydrazide material also undergoes necrosis and collapses (fig. 17, $B$ ). At this stage, the anatomic effects of the yellow dwarf virus and maleic hydrazide upon the phloem may be indistinguishable.

Fffects upon Tissues Other than Phloem. The effect of maleic hydrazide upon the apical meristem and the youngest shoot parts has been described in detail above in this paper. Gifford (1956) has pointed out the occurrence of a necrosis in the ground tissue associated with the vascular bundles and that of the pith and leaf mesophyll. Similar observations were made on the material used in the present study. The breakdown of the mesophyll, associated with a degeneration of the chloroplasts (fig. 20), was most pronounced and appeared earliest in the third leaf, although in the Bromus species the second leaf also showed a necrotic degeneration in the mesophyll. In the younger underdeveloped leaves the mesophyll and epidermis commonly became partially necrosed (figs. 14 and 15).

Gifford (1956) stressed the occurrence of gum in the tracheary elements and the more or less complete necrosis of the xylem. In addition to these features, some of the present material showed abundant tyloses in the xylem of the young shoot parts.

Three additional features need special mention: the occurrence of starch in the mesophyll; the phenomena associated with the exudation from the leaves; and the degeneration of stomata. The accumulation of carbohydrates, and specifically of starch, in plants treated with maleic hydrazide has been reported in the literature (Carlson, 1954; Currier et al., 1951; McIlrath, 1950). In the present study visible accumulations of carbohydrate-in the form of starch in the chloroplasts of the leaves-were found to be variable. No excessive amounts of starch were noted in Avena. In Hordeum and Bromus the amount of starch was much greater in the treated plants than in the controls. In Hordeum starch was abundant in the oldest leaves in the first collection but decreased in amount in the later collections. The two Bromus species showed a more consistent behavior. The first leaf had abundant starch, which increased in amount in the successive samplings. The second leaf had smaller amounts of starch but still much greater than the controls. The third leaf had no conspicuous accumulations of starch.

The condition of the leaves having exudate on their surfaces was basically similar to that of the exuding leaves in the yellow dwarf material: in both kinds of leaves the mesophyll was found to be undergoing a necrotic degeneration and disintegrated material-referred to here as gum-occurred in 
the intercellular spaces (compare fig. 11, $B, C$, and fig. 20). Here and there the gummous material that had accumulated in the substomatal chambers was found to be in contact, through an opening in the epidermis, with similar material on the surface of the leaf. Figure 20 illustrates such a relation, except that the mass of exudate released from the leaf had been separated from the exudate within the leaf during the technical processing of the material.

With regard to the yellow dwarf material the conclusion was reached that the exudate emerged from the leaf through the stomata. In the maleic hydra-

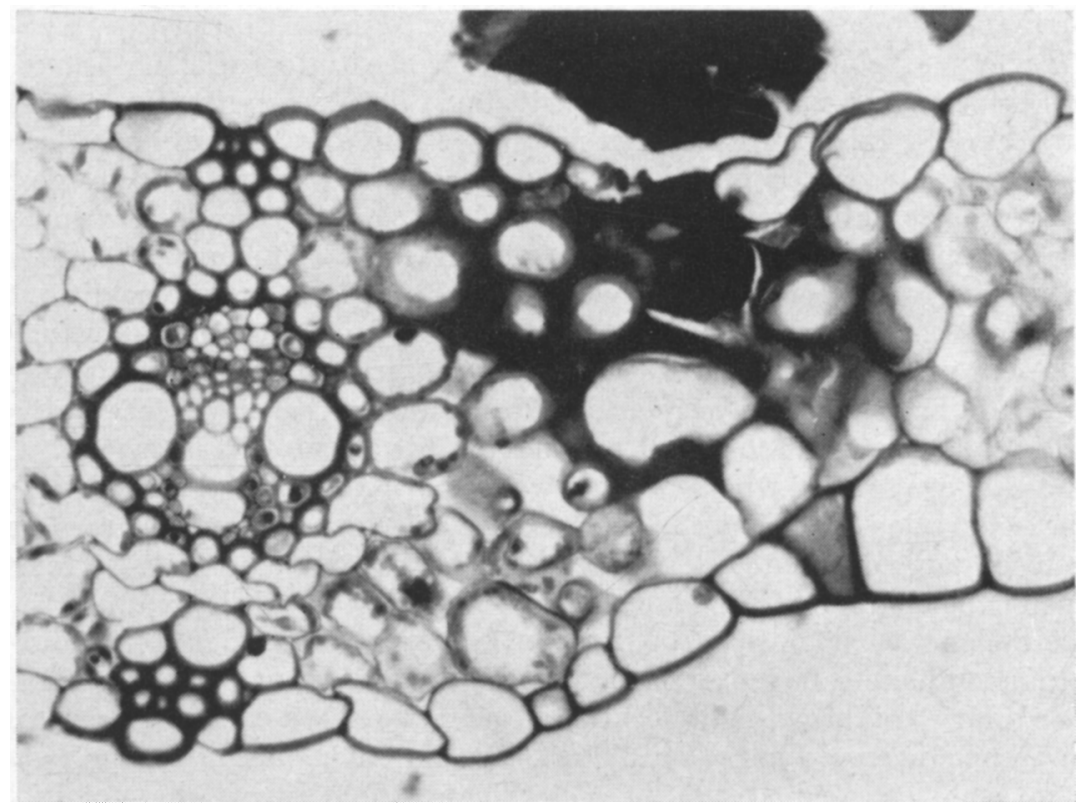

Fig. 20. Hordeum vulgare, barley. Maleic hydrazide. Leaf blade showing a vascular bundle, with phloem above and xylem below, at left. To right from the vascular bundle is necrosed mesophyll with gummous material filling a substomatal chamber. The stoma is degenerated. The exudate visible above section is part of same material that is contained in substomatal chamber. $(\times 320$. $)$

zide material many stomata were in various stages of degeneration and the exudate was often seen having emerged to the surface through openings that were devoid of guard cells (fig. 21, $D$; fig. 22, $C$ ).

The degeneration of the stomata ${ }^{7}$ assumes two aspects: fully developed stomata may undergo necrosis or the stomata may develop abnormally. The first condition is encountered in leaves that are advanced in development at the time of treatment, the second in younger leaves.

The normal development of the stomata of Gramineae is well known and is briefly illustrated in figure $21, A-C$. Before the leaf develops prominent intercellular spaces, certain unexpanded cells in the protoderm, the guard-

\footnotetext{
${ }^{7}$ The term stoma is used inclusively to denote the guard cells, the subsidiary cells, and the opening between the guard cells.
} 
cell mother cells (fig. 21, $A$ at $a$ ), become flanked by derivatives from two adjacent protodermal cells. These derivatives are the subsidiary cells (fig. $21, A$, at $c$ and to the right of $a$ ). The guard-cell mother cell divides into two guard cells ( $b$ in fig. 21, $B$ ). At this time a small intercellular space appears beneath the future stoma ( $d$ in fig. $21, B$ ). With further development of the leaf the two guard cells separate from each other along part of their contact surface. In the mature stoma (fig. $21, C$ ) the subsidiary cells appear considerably larger than the guard cells when seen in median section through the stoma, but much smaller than the adjacent ordinary epidermal cells. A large substomatal chamber occurs beneath the stoma ( $d$ in fig. 21, $C$ ).

A variety of conditions is encountered in the differentiating leaves of plants treated with maleic hydrazide: a stoma develops normally; a guardcell mother cell fails to divide; the mother cell divides but only one derivative differentiates into a guard cell (fig. $21, E$ ) ; subsidiary cells are absent (fig. $21, E$ ), or only one is present (fig. $21, F$ ), or two are present but are small and misshapen; finally-and probably most commonly in the lastformed leaves-no stomata differentiate. Despite all these abnormalities the substomatal chambers develop (fig. 21, $E, F$ ). In fact, substomatal chambers are present under openings that have neither guard cells nor subsidiary cells (fig. 21, $D$; fig. 22, $C$ ). This relationship merits further study. Tentatively one might suggest that the openings lacking the usual cells associated with the stomata are formed where stomata would normally have appeared. Stages in the separation of epidermal cells above large intercellular spaces have been frequently encountered. These openings then provide avenues for the escape of the exudate in the absence of stomata.

The degeneration of stomata in older leaves involves a necrosis and an eventual complete collapse of the subsidiary and the guard cells (fig. 22, $A$ ). The ordinary epidermal cells located adjacent to the degenerating stomata often become necrosed also (fig. 22, B). The exudate emerges through openings in such necrosed areas (fig. 20). These degenerative changes in the epidermis explain the previously mentioned occurrence of necrotic spots beneath the drops of exudate.

The abnormal development of the stomata and the necrosis of the normally differentiated stomata do not appear to be causally related to the phenomena responsible for the exudation. The degeneration of stomata may occur without an association with the exudate (fig. 22, $A, B$ ). Moreover, in plants affected with yellow dwarf no degeneration of stomata was observed in leaves with exudate. The abnormal development of the stomata in the plants treated with maleic hydrazide is probably connected with the abnormalities of growth and maturation of the leaves. The cause of degeneration of the fully developed stomata is, however, obscure.

Since some of the plants affected by the yellow dwarf virus show an inhibition of meristematic activity and associated abnormalities in differentiation comparable with those found in plants treated with maleic hydrazide (see especially the precociously maturing epidermis devoid of stomata in figures 7 and 14), defective stomata could be expected in the former plants also. This possibility has not been explored. 


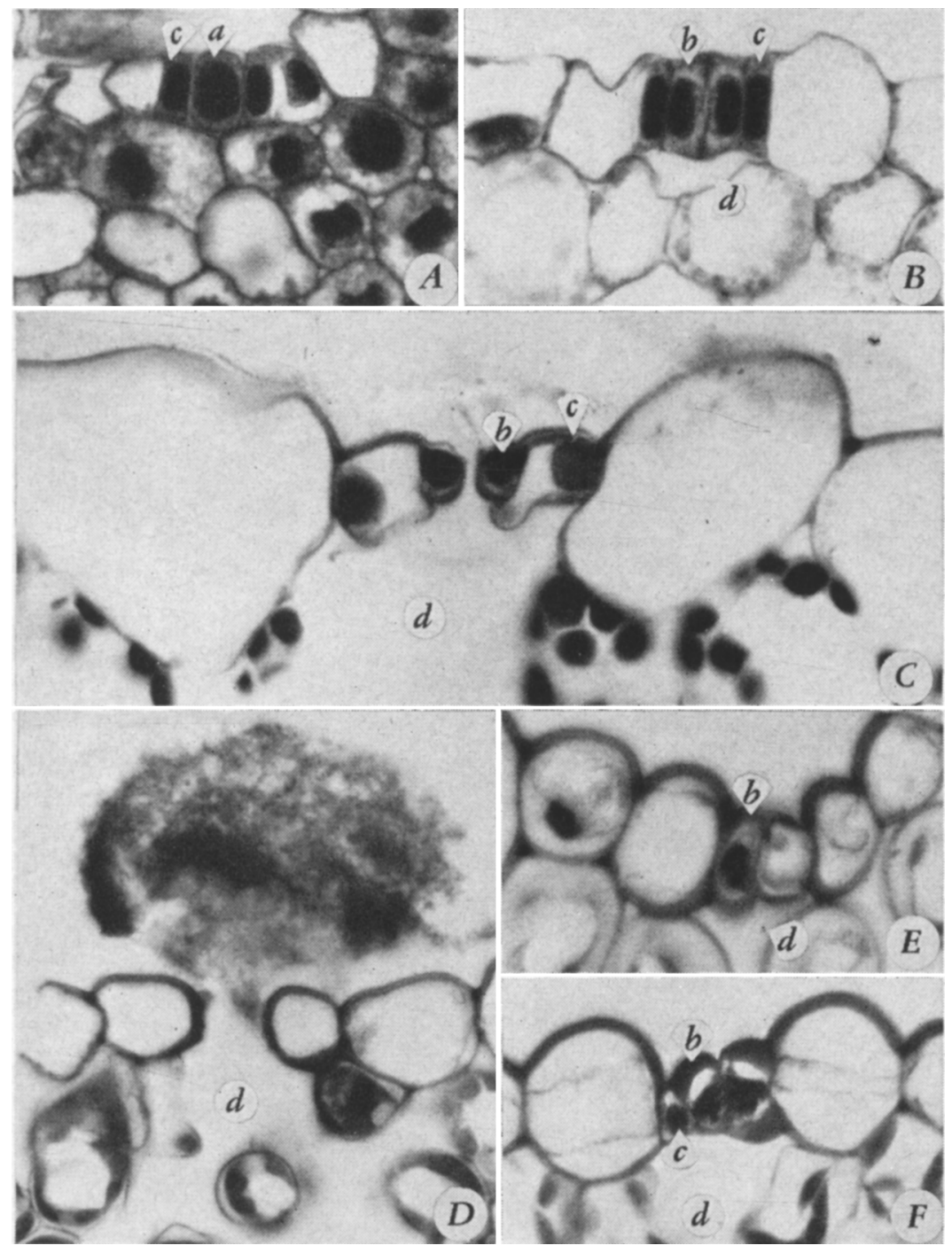

Fig. 21. Bromus rigidus, ripgut grass $(A-E)$ and Avena sativa, oat $(F)$. Maleic hydrazide $(D-F)$ and controls $(A-C) . A$ and $B$, Differentiating stomata. In $A$ guard-cell mother cell $(a)$ is still undivided but two subsidiary cells $(c)$, right and left, are present. In $B$, two young guard cells $(b)$ and two subsidiary cells $(c)$ are present. The substomatal intercellular space $(d)$ started to develop in $B$. $C$, Mature stoma with guard cells $(b)$, subsidiary cells $(c)$, and a substomatal chamber $(d) . D$, An opening in epidermis without guard cells, with excreted material above. $E$, Abnormally differentiating stoma, with only one guard cell $(b)$ having a thick wall. No subsidiary cells are present. $F$, Abnormal stoma, with only one guard cell $(b)$ associated with a subsidiary cell $(c)$. Sections of controls were made from fourth $(A)$, sixth $(B)$, and second $(C)$ leaves of plants collected $24(A$, $C)$ and $29(B)$ days after planting. $D$ is from third, $E$ and $F$ from fourth leaf of plants collected 24 days after planting and 9 days after treatment. Details are: $a$, guard-cell mother cell; $b$, guard cell; $c$, subsidiary cell; $d$, substomatal intercellular space. (All $\times 850$.) 

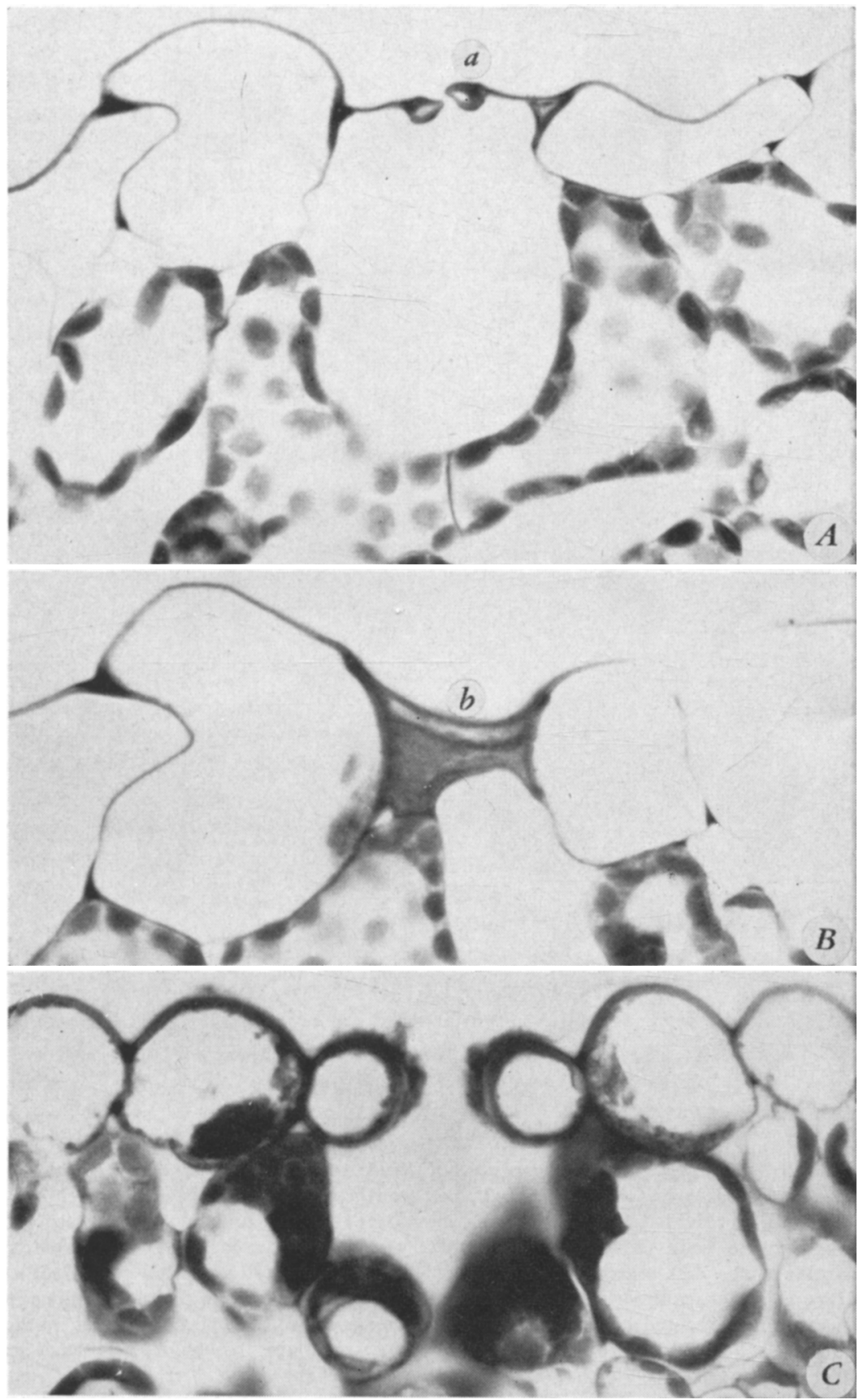

Fig. 22. Bromus rigidus. Maleic hydrazide. A, Degenerating stoma with collapsed subsidiary cells. $B$, Necrosed epidermal cell $(b)$. $C$, Opening in epidermis without guard cells. Necrosed cells line intercellular cavity. $A$ and $B$, from second, $C$, from third leaf of plants collected 24 days after planting and 9 days after treatment. Details are: $a$, guard cell; $b$, degenerating epidermal cell. (All $\times 850$.) 


\section{EFFECT OF THE VIRUS AND OF MALEIC HYDRAZIDE UPON THE ROOT}

Effect of Yellow Dwarf Virus. The degenerative changes in the vascular cylinder of root tips of plants affected by the yellow dwarf disease have been described in the first report on the anatomic effects of this disease (Esau, 1957). The significant feature of these changes is that they are initiated in cells adjacent to the earliest sieve elements to mature in the root. The cells in contact with such elements are pericyclic cells, usually two, and some phloem parenchyma cells (fig. $23, A$; fig. $26, B$ ). In diseased plants one or more of these cells may show first nuclear hypertrophy, then an increase in density and stainability of the entire protoplasts (cells right and left from the sieve element in figure $23, B$ ) and finally a complete necrosis (fig. $23, B$, the two pericyclic cells ; fig. $23, C$ ).

The positional relation of the degenerative changes to the sieve elements is not restricted to the roots that are just differentiating, but is evident in older roots also. A comparison of the affected older root in figure $24, B$, with its control (fig. 24, $A$ ) shows the abnormal density of staining and occurrence of necrosis in cells at each phloem pole. Sometimes the sieve elements themselves are filled with gum and the dense staining occurs in the parenchyma of the xylem also.

No conspicuous changes were noted in the apical meristems of most root tips. Sometimes a light staining of all cells in this region suggested a cessation of meristematic activity; and in an occasional root degenerative changes had spread to levels younger than those where the sieve elements were mature. Since only apparently intact root tips were collected, those with a possible complete necrosis of the apical meristem would have been missed. A breakdown of the meristems of lateral roots was noted in a few samples. In the Gramineae a lateral root originates opposite a phloem pole (fig. 25, $A$ ). In a diseased root the degeneration of the lateral root primordium appears to be initiated next to the sieve element in the parent root opposite which the lateral root originates (fig. 25, $B$ ).

As was pointed out earlier (Esau, 1957a) the root tips proved to be particularly useful for the recognition of the relation between the sieve elements and the inception of degeneration. The present study shows that the patterns of degeneration in older roots and in lateral root primordia lend additional support to the concept that virus injury spreads from the mature sieve elements to the adjacent cells.

In the shoot the localization of the first injury to the vicinity of sieve elements is less readily perceived because the early necrotic obliteration resembles the normal obliteration except in timing, severity of collapse, and presence of gumlike material. The root studies have clarified the sequence of events in the shoot.

Effect of Maleic Hydrazide. Since no evidence was obtained that changes induced by maleic hydrazide are initially localized to the site of the sieve elements in the shoot, it was obviously of interest to see whether this difference from the sequence of virus injury would be evident in the root also. 
The development of roots of plants treated with maleic hydrazide was found to be different from that of roots affected by the virus.

The familiar sequence in the early differentiation of vascular tissues in the root of a Gramineae is shown in figure 26. Although the various elements of the vascular cylinder-the protophloem $(a)$ and metaphloem $(c)$ sieve elements, the protoxylem $(b)$, early metaxylem $(d)$, and late metaxylem $(e)$ elements-may be recognized close to the apical meristem (fig. 26, $A$ ), the protophloem elements are the first to reach maturity (fig. $26, B$ ).

In the root of plants treated with maleic hydrazide the principal change is - as in the shoot - a cessation of meristematic activity and a maturation of tissues close to the apex (cf. Carlson, 1954 ; Compton, 1952). This differentiation is successively closer to the apex as the time interval between the treatment and the sampling increases. Figure 27, $A$, shows a section of a root from a plant sampled 5 days after the treatment. The section was taken at approximately the same distance from the apex as the control section in figure $26, A$. In the root from the treated plant the cells have lost their meristematic appearance and have enlarged considerably. Sieve elements are mature at this level (200 microns from the apex), whereas in the control shown in figure 26 these elements reached maturity about 600 microns from the apex. Moreover, the sieve elements in the treated root are considerably wider than normal. In the control root no secondary walls were present in any xylem elements at the very end of the series of available sections, 3 millimeters from the apex. In the root in figure $27, A$, secondary walls were initiated in some protoxylem cells $(b)$ at the level where the sieve elements just became mature.

A more striking evidence of the precocious maturation in the treated roots is shown in figure $27, B$, and figure 28 . These three sections were taken successively farther from the apex of the same root from a plant collected 20 days after the treatment. The maturation of the tissues in the vascular cylinder had reached the apex so that no meristem was left. The condition shown in figure $27, B$, at 80 microns from the apex-cells of uncertain identity, most of them very short and with secondary lignified walls, with no recognizable sieve elements among them-continued to the apex itself. Farther from the apex, at a level comparable with that of figure $26, A$, and figure $27, A$, the organization of the vascular cylinder was somewhat closer to the normal, but all cells were mature (fig. 28, $A$ ). The cells were larger and the walls thicker than normal and one sieve element ( $a$ at the left) was collapsed. Still farther from the apex the vascular cylinder had practically a normal organization (fig. $28, B$ ), except that it was completely mature at levels where the control root still lacked any secondary walls in the xylem.

The difference in the degree of degeneration at different levels of the same root is undoubtedly related to the timing in the effect of the chemical. The part of the root shown in figure $27, A$, was older than that in figure $28, A-$ or perhaps the latter part was not even present-when the plants were treated with maleic hydrazide. Similar relations were observed in the shoot where the youngest leaves showed the most extreme degenerative changes.

Thus the principal anatomic effect of maleic hydrazide upon the roots is that, as in the shoots, it inhibits meristematic activity and induces an abnormal enlargement of cells and a precocious maturation of tissues, in the 

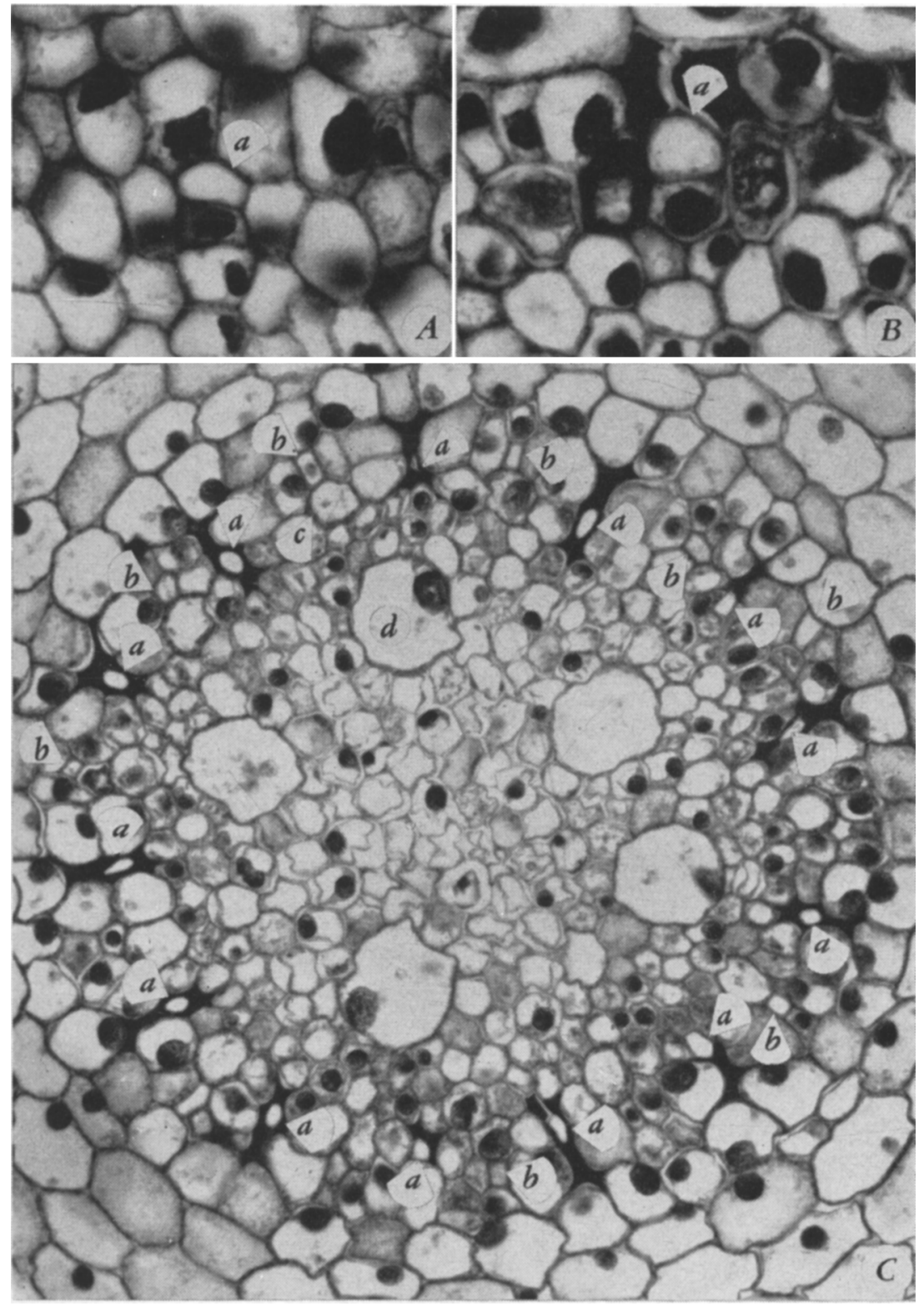

Fig. 23. Bromus mollis, soft chess grass $(A, B)$, and Triticum aestivum, wheat $(C)$. Yellow dwarf $(B, C)$ and control $(A)$. Root tips. $A$ and $B$, Mature sieve elements $(a)$ and surrounding parenchyma cells. In $B$ four cells touching the sieve element $(a)$, two right and left, and two above (in pericycle) are in stages of degeneration. $C$, Complete vascular cylinder (immature in the center). Cells in contact with mature sieve elements (a) are necrosed. $A$ and $B$, From plants collected 42 days after planting, and $B, 29$ days after inoculation; $C, 35$ days after planting and 25 days after inoculation. Details are: $a$, sieve element; $b$, protoxylem element; $c$, early metaxylem element (immature); $d$, late metaxylem element (immature). $(A, B, \times 850 ; C, \times 330$. 


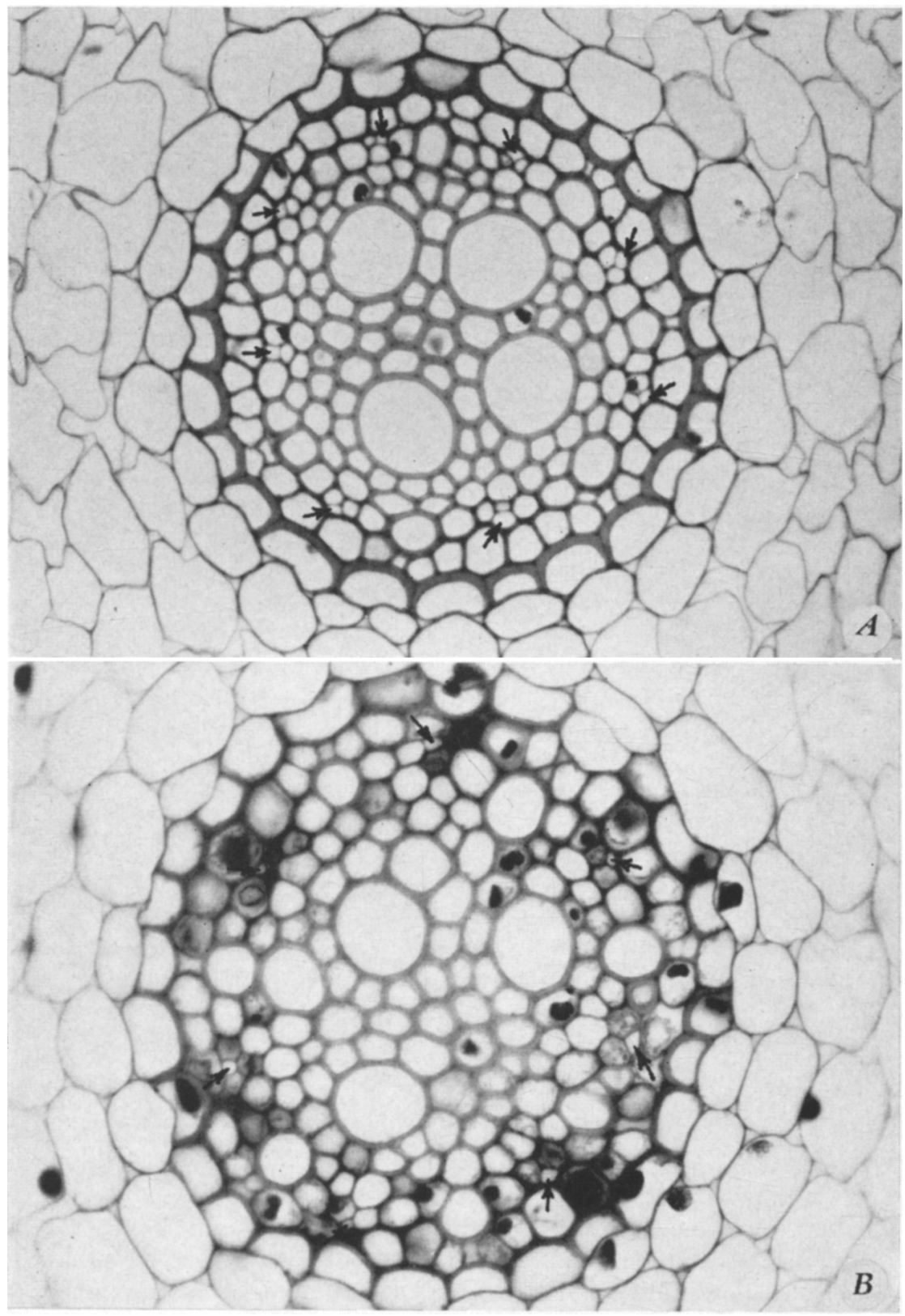

Fig. 24. Bromus mollis, soft chess grass. Yellow dwarf $(B)$ and control $(A)$. Vascular cylinders from mature roots, with earliest sieve elements indicated by arrows. Outside the sieve elements is pericycle, then endodermis with thickened radial and inner tangential cell walls. In $B$ the cells adjacent to first sieve elements are in various stages of degeneration. The rots are from plants collected 42 days after planting and $B 29$ days after inoculation. (Both $\times 435$.) 


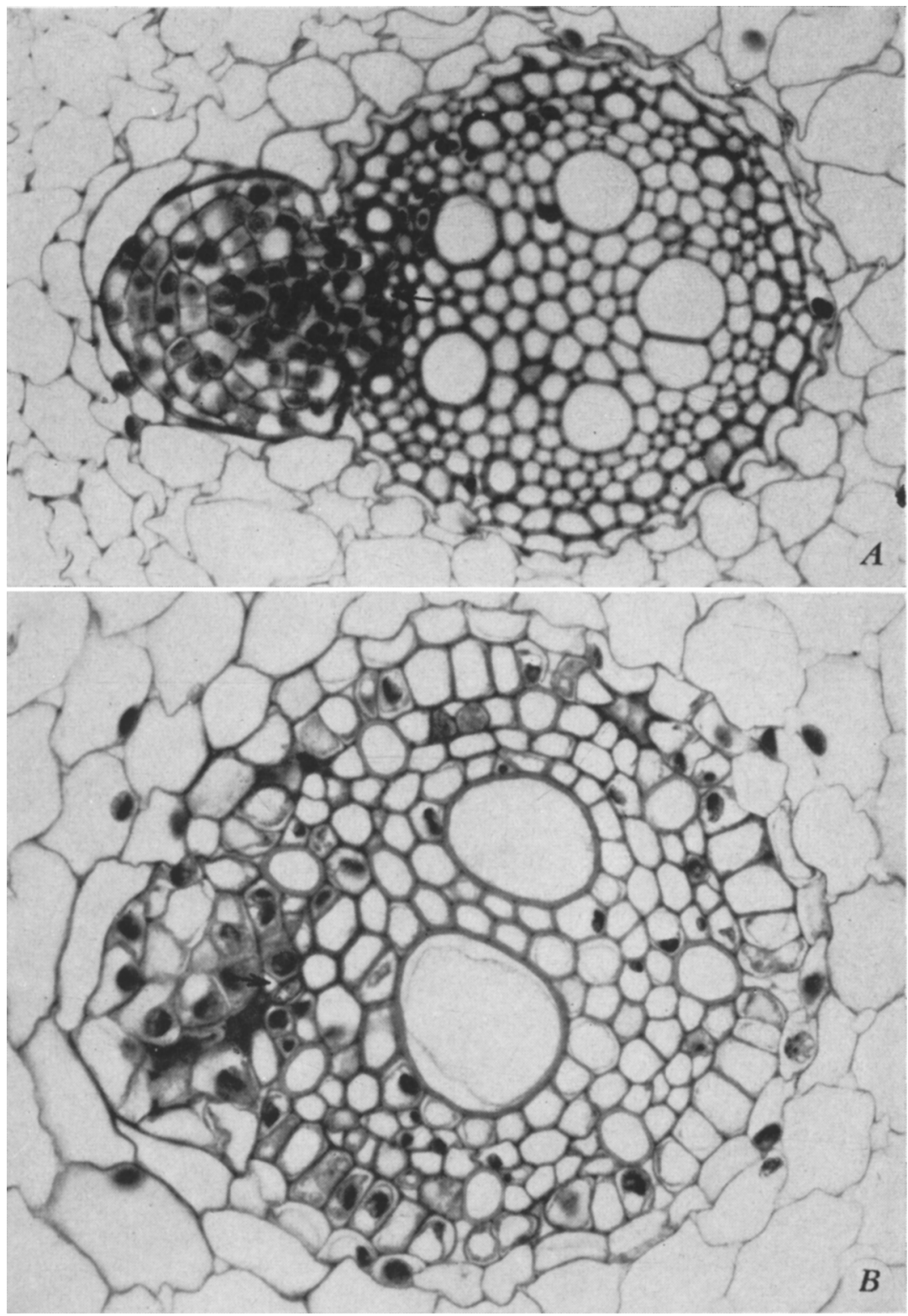

Fig. 25. Bromus mollis, soft chess grass $(A)$; Avena sativa, oat $(B)$. Yellow dwarf $(B)$ and control $(A)$. Vascular cylinders from almost mature roots, each with a lateral root primordium at left. $A$ depicts appearance of a normal lateral-root primordium in a Gramineae plant. The primordium arose opposite a sieve element (arrow). In $B$ the lateral-root primordium, which also arose opposite a sieve element (arrow), has undergone partial necrosis. The plant used for $B$ was collected 37 days after planting and 27 days after inoculation. $(A, \times 320 ; B, \times 411$. 

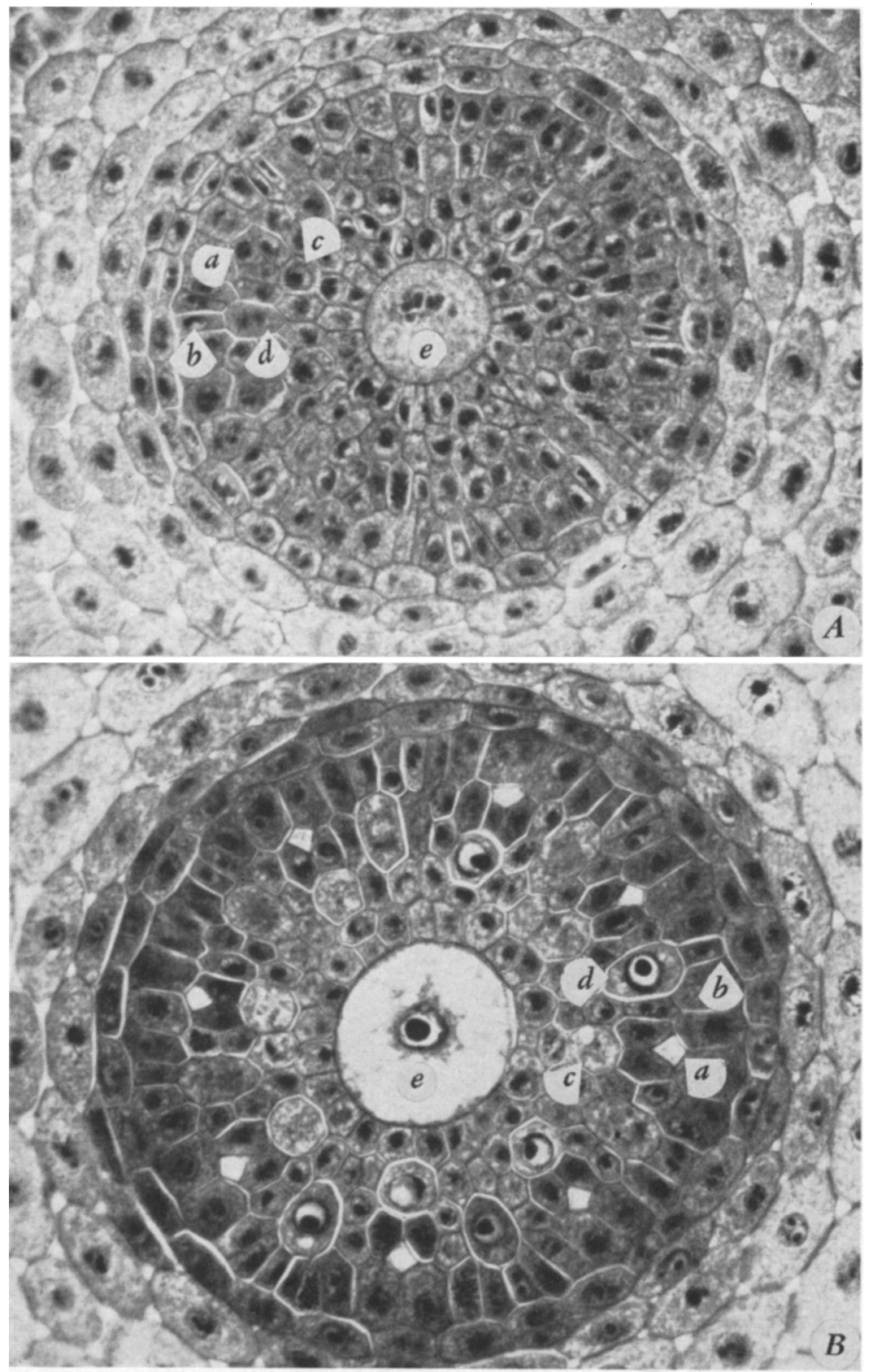

Fig. 26. Hordeum vulgare, barley. Control for figures 27 and 28. Vascular cylinder of a root tip taken 240 microns $(A)$ and 750 microns $(B)$ from apical meristem. The only mature vascular elements are the sieve elements $(a)$ in $B$. Details are: $a$, protophloem sieve element; $b$, protoxylem element (within the pericycle); $c$, metaphloem sieve element; $d$, early metaxylem element; $e$, late metaxylem element. (Both $\times 425$.) 


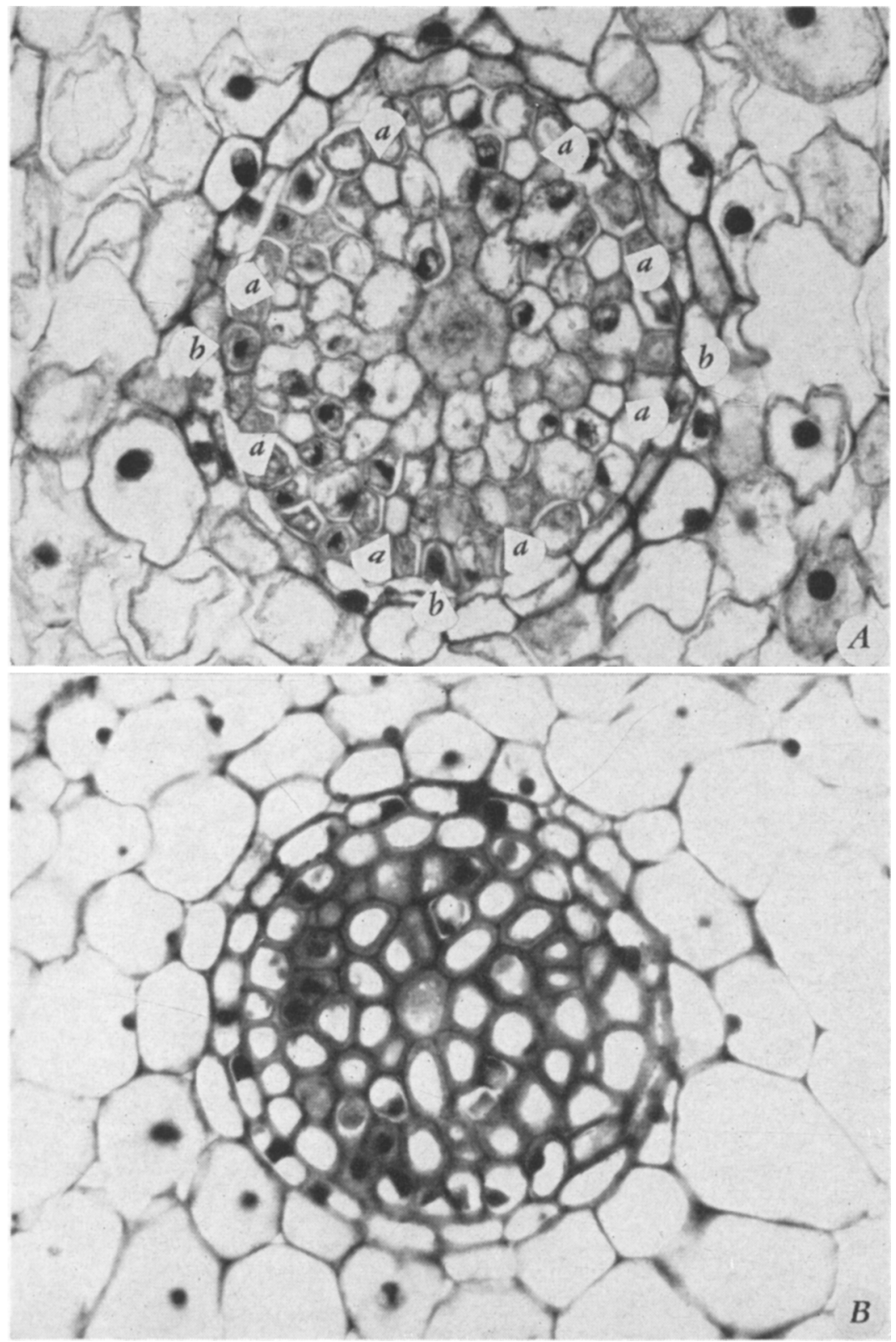

Fig. 27. Hordeum vulgare, barley. Maleic hydrazide. (Control in figure 26.) Vascular cylinders of root tips from plants collected 5 days $(A)$ and 20 days $(B)$ after treatment. The section in $A$ was taken 200 microns, in $B 80$ microns from apex. The sieve elements $(a)$ are mature in $A$ and some of the protoxylem elements $(b)$, within the pericycle, started to form secondary walls. In $B$, no sieve elements can be recognized at this level. Almost all cells have thick secondary lignified walls with prominent pits. Details are: $a$, sieve element; $b$, protoxylem element. (Both $\times 425$.) 

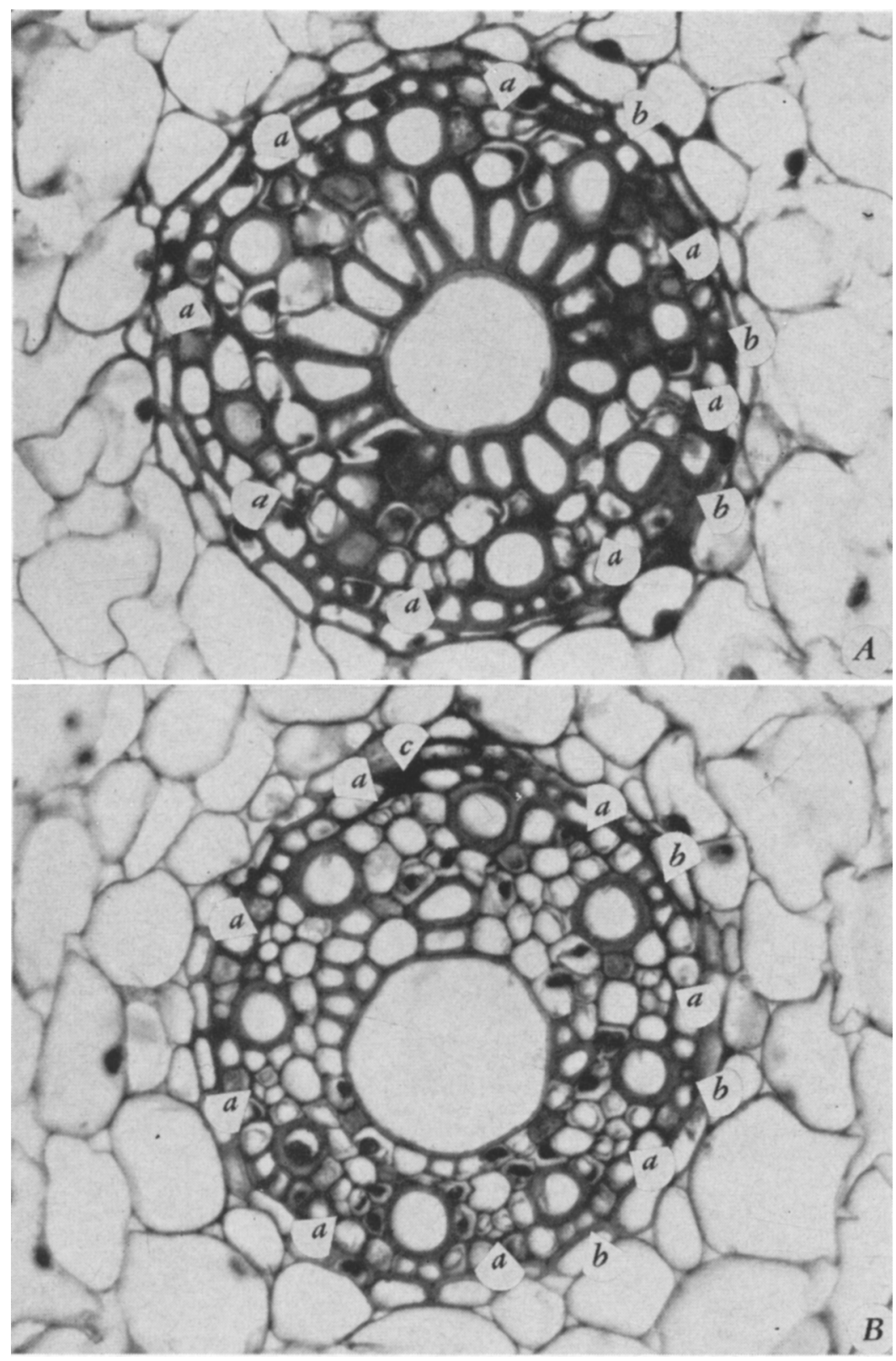

Fig. 28. Hordeum vulgare, barley. Maleic hydrazide. (Control in figure 26.) Vascular cylinder of same root used for fig. $27, B$, taken 260 microns $(A)$ and 1,480 microns $(B)$ from apex. The cylinder is wider and individual cells larger in $A$ than in $B$. The cell arrangement is more normal in $B$ than in $A$. Thus, abnormal structure is more pronounced closer to apex. Details are: $a$, sieve element (necrosed at the left in $A$ ); $b$, protoxylem element; $c$, necrosed pericyclic cell. (Both $\times 425$.) 
sense that the no longer active meristem is replaced by mature tissues. The enlargement of the cortical cells is so great that the root tip appears swollen (cf. also Carlson, 1954, and Compton, 1952). The vascular cylinder, however, is not necessarily wider than that of normal roots since it becomes deficient in cell numbers when the chemical begins to act upon the root before cell division is completed.

The developments just reviewed suggest no relation between the sieve elements and the inception of the characteristic degenerative changes induced in the roots by maleic hydrazide. The necrosed cells encountered were rarely located next to the sieve elements (fig. $28, B$, at $c$ ) ; usually they occurred with no relation to the sieve elements. Thus the structural changes in the root parallel those in the shoot except that the precocious maturation of tissues is more graphically expressed because of the simpler structure of the root.

\section{DISCUSSION}

Relation of Yellow Dwarf Virus to Tissues of the Host. The degenerative changes in differentiating leaves and roots of plants affected by the yellow dwarf virus strongly suggest that the virus is translocated in the phloem and that these changes, which are at first localized in the phloem and the immediately adjacent tissues, are primary in nature. The indication of a close relation betwen the virus and the phloem tissue is supported by Allen's (1956) studies on the feeding habit of one of the vectors of the yellow dwarf virus. Over 77 per cent of the feeding tracts left in the host tissues by the apple grain aphid, Rhopalosiphum prunifoliae, ended in the phloem. Allen also found that the staining combinations developed for the purpose of identifying the presence of viruses in plant tissues revealed "typical virus reactions" in the phloem and adjacent tissues, or only in the phloem, of axis and leaves of barley and oat. Allen's attempts to determine the method of translocation of the virus gave no conclusive results; however, the data obtained do not contradict the idea that the virus moves within the phloem.

Yellow Dwarf Virus Compared with Other Phloem-Affecting Viruses. The relation of the yellow dwarf virus to the other phloem-affecting viruses was discussed in the first report on the anatomic effects of this virus (Esau, $1957 a$ ). Briefly restated, the yellow dwarf virus may be grouped with those viruses that induce, as a principal disturbance in the phloem, a necrosis of sieve elements and their companion cells. It contrasts with those phloemlimited viruses that induce hyperplastic growth in the phloem (e.g., curly top and aster yellows viruses). One might speak of stimulative and nonstimulative effects of viruses-or, simply, stimulative and nonstimulative viruses - to characterize the presence and absence of a tendency to stimulate an increase in the number of cells in the affected tissues. Subsequently the hyperplastic phloem undergoes necrosis so that a degeneration of the phloem culminating in necrosis is characteristic of diseases caused by both kinds of viruses. Also in both kinds of disease hypertrophy and hyperplasia may occur in the form of wound-healing reactions near the collapsing phloem cells and also independently in tissues outside the phloem, probably as secondary reactions. 
Among the viruses promoting hyperplastic growth, those inducing the diseases called curly top (e.g., Esau, 1941), aster yellows (Girolami, 1955), bunchy top of banana (Magee, 1940), and phloem necrosis of elm (McLean, 1944) have been found exhibiting their first anatomic effects in cells located next to the first mature sieve elements at a given level of root or shoot. With regard to the viruses inducing a necrosis in the phloem without any pronounced growth changes preceding the death of cells, Schneider (1945) observed a necrosis of the earliest sieve elements in the shoots of the peach infected with the virus of the buckskin disease. The evidence that a nonstimulative virus may induce the initial histologic changes in connection with earliest sieve elements, however, has been provided most convincingly by the Gramineae affected with the yellow dwarf disease.

The stimulative effects of viruses inducing phloem hyperplasia may be recognized only in tissues that are still capable of meristematic activity. This relation has been recognized particularly clearly in the curly top disease (Esau, 1935, 1941): leaves and roots that were infected in early stages of growth developed hyperplasia in the youngest parts of the phloem, leaves and roots affected later showed normal obliteration in the earlier phloem and hyperplastic changes in the later phloem, both the later primary and the secondary phloem. Thus far only one exception was recorded: cotyledons of sugar beet seedlings through which the virus is introduced into the plant may show a necrotic obliteration in the older parts of the phloem before the hyperplastic changes occur in the younger phloem (Esau, 1957b).

The yellow dwarf virus induces similar changes in both the younger and the older phloem-necrosis and collapse of cells in a tissue with a more or less normal arrangement of cells. The type of degeneration provoked by this virus is less specific than that induced by the stimulative viruses and appears to be more often paralleled by actions of agencies other than viruses. If the tissue organization is altered in the yellow dwarf material-excess of phloem over xylem, absence of companion cells where they normally occur, abnormally wide sieve elements, contact between sieve elements and tracheary elements in other than the smallest veins (where such contact is common, cf. Esau, 1953, p. 428) - these changes may be related to an inhibition of meristematic activity and a precocious maturation of tissues resulting from a suppression of growth.

A general stunting characterizes plants affected by representatives of both kinds of viruses, stimulative and nonstimulative. One may assume that the degeneration of the phloem is at least a partial cause of the reduced growth of the diseased plants. Caution should be exercised, however, in relating the various symptoms to one another. Wilson (1955), for example, concluded that leaf rolling and phloem necrosis (identified by phloroglucinol-HCl test) are independent symptoms of the potato leaf roll disease, not causally related to one another because they are affected differentially by nutrient supply and shading, and each can occur without the other.

Comparative Effects of the Yellow Dwarf Virus and Maleic Hydrazide. Apparently the present study is the first to give a comparison of anatomic effects of a virus and a growth-regulating substance upon the same species. With regard to the field of developmental anatomy a comparison of this kind 
is pertinent because of the frequent similarities in the external effects of viruses and growth-regulating substances. The selection of maleic hydrazide for a comparison with the yellow dwarf virus was prompted by the remarkable similarities in the external changes brought about by these two agencies. Furthermore, a preliminary observation on yellow dwarf plants suggested a resemblance between the phloem degeneration in these plants and those treated with maleic hydrazide (Gifford, 1956; McIlrath, 1950; Struckmeyer, 1953). This study has disclosed some further similarities: absence of growthstimulative effects in the phloem; breakdown of mesophyll in leaves producing the exudate of a viscous fluid; and the depression of the activity of the apical meristem as revealed by the reduction in the number of leaves initiated on the plant and the reduction of distance (plastochronic and actual) between the apex and the leaf with the first mature vascular elements.

A significant difference is observed, however, in the initial effects in the differentiating parts of shoots and roots. The initial virus injury is recognizable in the young phloem, whereas the effect of maleic hydrazide is evident first in the meristems. The virus thus appears to be closely associated with the phloem, whereas the maleic hydrazide shows no such specific relation to this tissue. This interpretation is not meant to imply that the maleic hydrazide does not enter the phloem-in the older plant parts the phloem is similarly injured by both agencies-but on the basis of the anatomic effects it seems doubtful that the phloem constitutes the sole path of movement of maleic hydrazide.

In evaluating the differences and similarities in the effects of the yellow dwarf virus and the maleic hydrazide it is of interest to note that both agencies may be characterized as nonstimulative in the sense that neither induces primary hyperplastic growth phenomena. Many other growth-regulating substances provoke extensive cell proliferations, whereas maleic hydrazide is principally a growth-inhibiting substance (Naylor and Davis, 1950; Nickell, 1953). ${ }^{8}$

The inhibitory effect of maleic hydrazide apparently finds a partial explanation in the observations that an antagonistic action exists between the maleic hydrazide and the auxins. According to Leopold and Klein (1952), maleic hydrazide inhibits growth in the absence of auxin and an addition of auxin completely relieves the inhibition by low concentrations of maleic hydrazide. Kulescha (1955) reports that, in tissue cultures, maleic hydrazide inhibits the action of indole-acetic acid, 2,4-D, and naphtoxy-acetic acid, although it does not reduce the content of these chemicals.

We have no information on the possible relation between the yellow dwarf virus and auxins. Such relation has been studied, however, with reference to certain other viruses. According to Jahnel (1937, 1939), virus-infected potato plants contain less growth-regulating substance and react less strongly to an application of such substances than healthy plants. Pavillard (1953) reports that tobacco mosaic virus causes an initial inhibition of growth which is associated with a reduction in the amount of auxin. If viruses affect the content of auxins, phloem degeneration-if it occurs-may not be the principal cause of the stunting of plants.

\footnotetext{
${ }^{8}$ Muzik and Cruzado, however, reported stimulative action of low concentrations of maleic hydrazide on cultured bean segments (Plant Physiol. Suppl. $32:$ LV, 1957).
} 
In the present experiments the effect of maleic hydrazide upon the plants was more rapid and stronger than that of the yellow dwarf virus. This comparison is of limited value, however, because the effect produced by maleic hydrazide depends on the concentration used; and it is not known what concentration of this chemical should be chosen for a comparison with the action of the virus.

Effect of Maleic Hydrazide upon Growth. The suppression of growth has been studied by many workers who agree that the primary effect of the chemical is the interference with mitosis and that this effect is followed by a precocious maturation of tissues (Carlson, 1954 ; Compton, 1952 ; Darlington and McLeish, 1951; Deyson and Rollen, 1951; Gifford, 1956; Greulach and Haesloop, 1954; Mericle et al., 1955; Naylor and Davis, 1950). Before the cells mature they may enlarge abnormally.

The effect of maleic hydrazide on cell enlargement is variable. Some report an inhibition of cell enlargement (Watson, 1952), others an abnormal increase in cell size (McIlrath, 1950; Struckmeyer, 1953), or both an inhibition and a promotion of cell growth in different regions of the same plant (Greulach and Haesloop, 1954). According to Deyson and Rollen (1951), the inhibition of cellular elongation by maleic hydrazide occurs at a later stage than the inhibition of mitosis. Greulach and Haesloop (1954) have carefully analyzed the problem of cell enlargement and concluded that the effect of maleic hydrazide may range from inhibition through no effect to promotion of enlargement; and that the prevailing situation determines the kind and degree of difference between the treated plants and the controls in the thickness of stems and leaves.

In view of the variability in the effect of maleic hydrazide on cell enlargement it is important to have an appropriate point of reference for comparison of affected and nonaffected plant parts. Some of the figures in the present paper illustrate the problem. If in figure 15 one compares the apical meristems of the two shoots, one must conclude that maleic hydrazide has induced the cells to enlarge abnormally (fig. 15, B). A similar conclusion may be drawn from a comparison of leaf 4 in figure 13, $A$, with leaf 6 in figure 12 , $A$, both of which are leaves located at the fourth node below the apex. If, however, leaf 4 in figure $13, A$, is compared with its chronologically equivalent leaf in the control, that is, the fourth leaf from below (leaf 4 in fig. 12, $A$ ) then the effect of maleic hydrazide must be interpreted as an inhibition of cell enlargement. In fact, leaf 4 in the control had not yet completed its growth and at maturity its cells would have been even larger than shown. On the contrary, the equivalent leaf in the treated plant was almost mature and its cells would have enlarged probably no more than to the size of cells in leaf 4 in figure $13, B$, which occurred on a treated plant collected 12 days later than the one in figure $13, A$. Thus, close to the meristems maleic hydrazide commonly induces a precocious enlargement of cells, but since this enlargement is associated with a general precocious maturation of tissues, the final sizes reached by the cells may be below those ultimately found in the equivalent parts of the control plants. Similar considerations may be applied to the comparison of the thickness of leaves and stems.

Watson (1952) compared leaves (and apparently stem nodes also) of the 
same plastochron when counted from the base of the plant upward, and he found an inhibition of cell enlargement in Phaseolus treated with maleic hydrazide. McIlrath (1950), working with cotton, also compared leaves at equivalent nodes when counted from the base of the plant up. In contrast to Watson, he found, in the treated plants, an increase in leaf thickness resulting from an increase in cell size. His convincing conclusion is based on a statistical analysis of the data. One might suggest that the timing of the effect of the chemical in relation to the stage of development of the leaf also plays a major role in determining the final size of cells and organs. As Greulach and Haesloop (1954, p. 49) have aptly expressed it, the effect of maleic hydrazide on cell enlargement is "a rather delicately balanced mechanism in which cell environment plays a major determinative role."

The precociousness of maturation has been observed in roots, shoots, and embryos (Carlson, 1954; Compton, 1952 ; Gifford, 1956; Mericle et al., 1955). This feature appears to be associated with the cessation of meristematic activity and is encountered in plants treated with other growth-retarding agencies (e.g., radiation from $\mathrm{P}^{32}$, Mackie et al., 1952). Differences in levels of maturation beneath the apical meristems occur also in normal untreated plants in relation to the activity of meristems. Heimsch (1951) has demonstrated particularly graphically, by the use of barley roots, that mature vascular elements occur closer to the apical meristem during slow growth than during rapid growth.

The Exudate from Diseased and from Treated Leaves. The exudation of the viscous fluid in plants affected by the virus and treated with maleic hydrazide appears to be associated with some disorganization of the leaf tissues. Leaves with exudate have been found to have mesophyll in various stages of degeneration. Since the drops of the exudate in plants treated with maleic hydrazide contain mostly sucrose (Currier et al., 1951), one might assume that the material is derived from the phloem. However, no direct connection between the phloem and the exudate on the surface of the leaf was observed; no breaks in the continuity of the tissues surrounding the phloem were found. Moreover, the exudate appears on both surfaces of the leaf and not only on the phloem side (Currier et al., 1951; also confirmed in the present study). As was mentioned previously, in sugar beet leaves affected by curly top and forming a sugary exudate there are breaks in tissues leading from the phloem to the surface (Bennett and Esau, 1936) and the drops appear on the phloem side of the leaf (Severin, 1929).

In plants treated with maleic hydrazide the exudate was either amorphous (fig. 20) or granular-reticulate (fig. 21, D). The material in the intercellular spaces in the diseased oat leaves from Illinois appeared in many sections as shown in figure 11, $C$ : it could have been described as fibrous or even crystalline. In some other sections it was granular or amorphous. Dr. Wm. B. Hewitt suggested (personal communication) that the crystalline appearance might be associated with a presence of virus in the exudate. The matter needs further study.

Naylor and Davis (1950) have suggested that the exudate from plants treated with maleic hydrazide came from the intercellular spaces through the stomata. The same conclusion was reached in the present study. The stomata, 
however, are often degenerated and the exudate is released through openings occurring in the same positions as stomata but lacking the cells usually associated with the stomata. The significance of the degeneration of the stomata is not clear. The effect on the development of the stomata is understandable: the precocious maturation interferes with the development of the stomata which normally differentiate in relatively late stages of leaf development; but there is also a necrosis of stomata that appears to have developed normally, and it is not necessarily associated with the phenomenon of exudation.

Abnormal development of stomata has been observed in plants treated with colchicine (Weissenböck, 1949, 1950). Most commonly the guard-cell mother cell failed to divide, but it developed characteristics similar to those of normal guard cells (e.g., chloroplasts, thick walls), and substomatal chambers were formed under these undivided cells. Agents other than colchicine are known to induce abnormal development of stomata (literature in Weissenböck, 1950).

\section{SUMMARY}

Infection with the virus of barley yellow dwarf disease and treatment with maleic hydrazide produce many similar external and internal degenerative changes. The elongation of the leaves and the initiation of new leaves are inhibited. Necrosis occurs in the phloem, involving sieve elements, companion cells, and parenchyma cells. Necrosis may occur also outside the phloem-in the xylem and in the ground parenchyma. In leaves that show sugary exudate on the surface, the mesophyll is undergoing necrosis. The exudate appears to emerge through the stomata, which are often degenerated in the plants treated with maleic hydrazide.

A significant difference is observed between the initial effect of the virus and that of maleic hydrazide in the growing parts of shoot and root. Virus injury is first recognized, anatomically, in the young phloem, whereas the first effect of maleic hydrazide is expressed in the inhibition of meristematic activity. The initial derangement in the phloem induced by the virus is of such a nature that the existence of a close relation between the virus and the phloem may be inferred: the virus seems to move in the mature sieve elements. Maleic hydrazide does not appear to be specifically associated with the phloem, but it also probably enters the phloem since in older phloem it induces degenerative changes similar to those found in the yellow dwarf plants.

The yellow dwarf virus belongs to that group of phloem-affecting viruses that have no stimulative effects upon the tissue: no hyperplasia precedes the necrosis. Similarly, maleic hydrazide contrasts with many other growthregulating substances in that it does not stimulate cell proliferation, at least under the experimental conditions of the present study. 


\section{LITERATURE CITED}

Allen, T. C., JR.

1956. Geographical distribution, strains, and plant tissue location of the barley yellowdwarf virus. Univ. of Calif. (Thesis).

Allen, T. C., JR., and B. R. Houston

1956. Geographical distribution of the barley yellow-dwarf virus. Plant Disease Rptr. 40: 21-25.

BENNETT, C. W., and K. EsAU

1936. Further studies on the relation of the curly top virus to plant tissues. Jour. Agr. Res. 53: 595-620.

BONNETT, O. T.

1935. The development of the barley spike. Jour. Agr. Res. 51: 451-57.

1936. The development of the wheat spike. Jour. Agr. Res. 53: 445-51.

1937. The development of the oat panicle. Jour. Agr. Res. 54: 927-31.

Carlson, John B.

1954. Cytohistological responses of plant meristems to maleic hydrazide. Iowa State Col. Jour. Sci. 29: 105-28.

COMPTON, WINIFRED

1952. The effects of maleic hydrazide on growth and cell division in Pisum sativum. Torrey Bot. Club. Bul. 79: 205-11.

Currier, H. B., and A. S. Crafts

1950. Maleic hydrazide, a selective herbicide. Science 111: 152-53.

Currier, H. B., B. E. DAy, and A. S. Crafts

1951. Some effects of maleic hydrazide on plants. Bot. Gaz. 112: 272-80.

Darlington, C. D., and J. McLeish

1951. Action of maleic hydrazide on the cell. Nature 167: 407-08.

Deyson, Guy, and Alice Rollen

1951. The antimitotic action of maleic hydrazide. Acad. de Sci. Compt. Rend. 233: 820-21.

EsAU, K.

1935. Initial localization and subsequent spread of curly-top symptoms in the sugar beet. Hilgardia $9(8)$ : $397-436$.

1941. Phloem anatomy of tobacco affected with curly top and mosaic. Hilgardia 13(8) : 437-90.

1948. Some anatomical aspects of plant virus disease problems. II. Bot. Rev. 14: 413-49.

1953. Plant anatomy. 735 p. New York, John Wiley \& Sons.

1956. An anatomist's view of virus diseases. Amer. Jour. Bot. 43: 739-48.

1957a. Phloem degeneration in Gramineae affected by the barley yellow-dwarf virus. Amer. Jour. Bot. 44: 245-51.

$1957 \mathrm{~b}$. Curly top symptoms in an inoculated cotyledon of the sugar beet. Hilgardia $27(1): 1-14$.

Evans, M. W., and F. O. Grover

1940. Developmental morphology of the growing point of the shoot and the inflorescence in grasses. Jour. Agr. Res. 61: 481-520.

GiFFord, E. M., JR.

1956. Some anatomical and cytological responses of barley to maleic hydrazide. Amer. Jour. Bot. 43: 72-80.

Girolami, Guido

1955. Comparative anatomical effects of the curly-top and aster-yellows viruses on the flax plant. Bot. Gaz. 116: 305-22.

Greulach, V. A., and J. G. Haesloop

1954. Some effects of maleic hydrazide on internode elongation and stem anatomy. Amer. Jour. Bot. 41: 44-50.

Heimsch, Charles

1951. Development of vascular tissues in barley roots. Amer. Jour. Bot. 38: 523-37.

НІтснсоск, A. S.

1951. Manual of the grasses of the United States. U. S. Dept. Agr. Misc. Publ. 200. 
JAHNEL, HeLmut

1937. Wuchsstoffuntersuchungen an abbaukranken Kartoffeln. Phytopath. Ztschr. 10: $113-17$.

1939. Wuchsstoffuntersuchungen an abbaukranken Kartoffeln. II. Phytopath. Ztschr. 12: $312-17$.

Kulescha, Zoia

1955. Action de l'hydrazide maléique sur la teneur en auxine des tissus de topinambour cultivés en présence de diverses substances de division. Acta Bot. Neerl. 4: 404-09.

LEOPOLD, A. C., and W. H. KLein

1952. Maleic hydrazide as an anti-auxin. Physiologia Plantarum 5: 91-99.

Mackie, Ruth W., J. M. Blume, and C. E. Hagen

1952. Histological changes induced in barley plants by radiation from $\mathrm{P}^{32}$. Amer. Jour. Bot. 39: 229-37.

MAGeE, C. J. P.

1940. Pathological changes in the phloem and neighbouring tissues of the banana (Musa Cavendishii Lamb.) eaused by the bunchy-top virus. Dept. Agr. New South Wales Sci. Bul. 67.

McIlrath, W. J.

1950. Responses of the cotton plant to maleic hydrazide. Amer. Jour. Bot. 37: 816-19.

MCLean, D. M.

1944. Histo-pathologic changes in the phloem of American elm affected with the virus causing phloem necrosis. Phytopathology 34: 818-26.

Mericle, L. W., A. M. Eunus, and R. P. Mericle

1955. Effects of maleic hydrazide on embryologic development. I. Avena sativa. Bot. Gaz. 117: 142-47.

NaYlor, A. W., and E. A. Davis

1950. Maleic hydrazide as a plant growth inhibitor. Bot. Gaz. 112: 112-26.

Nickell, L. G.

1953. Effect of maleic hydrazide on normal and atypical growth of Rumex acetosa. Amer. Jour. Bot. 40: 1-3.

Oswald, J. W., and B. R. Houston

1953a. The yellow-dwarf virus disease of cereal crops. Phytopathology 43: 128-36.

$1953 b$. Host range and epiphytology of the cereal yellow-dwarf disease. Phytopathology 43: 309-13.

Pavilitard, Jean

1953. Contribution a l'étude de la croissance des plantes virosées: virus et auxines. Thesis. Univ. of Paris. Ser. A, No. 2674, 201 p.

SCHNEIDER, HENRY

1945. Anatomy of buckskin-diseased peach and cherry. Phytopathology 35: 610-35.

Severin, H. H. P.

1929. Curly top symptoms on the sugar beet. California Agr. Expt. Sta. Bul. 465.

Sharman, B. C.

1947. The biology and developmental morphology of the shoot apex in the Gramineae. New Phytologist 46: 20-34.

SHeFField, F. M. L.

1943. Value of phloem necrosis in the diagnosis of potato leaf-roll. Ann. Appl. Biol. 30: $131-36$.

STRUCK MEYER, B. ESTHER

1953. The effect of maleic hydrazide on the anatomical structure of Croft Easter lilies. Amer. Jour. Bot. 40: 25-29.

TAKESHITA, R. M.

1956. Identity of the oat red-leaf virus with the barley yellow-dwarf virus. Phytopathology 46: 436-40.

WATSON, D. P.

1952. Retardation in cell development in leaf and flower buds of Phaseolus vulgaris $\mathrm{L}$. from foliar applications of maleic hydrazide. Torrey Bot. Club Bul. 79: 235-41. 
Weissenböck, KonRAD

1949. Studien an colchizinierten Pflanzen. I. Teil. Anatomische Untersuchungen. Phyton 1: 282-300.

1950. Studien an colchizinierton Pflanzen. II. Teil. Protoplasmatische Untersuchungen. Phyton 2: 134-52.

WILson, J. H.

1955. Effects of nutrition and light intensity on symptoms of leaf roll virus infection in the potato plant. Ann. Appl. Biol. 43: 273-87. 
The journal Hilgardia is published at irregular intervals, in volumes of about 600 pages. The number of issues per volume varies.

Subscriptions are not sold. The periodical is sent as published only to libraries, or to institutions in foreign countries having publications to offer in exchange.

You may obtain a single copy of any issue free, as long as the supply lasts; please request by volume and issue number from:

Agricultural Publications

Room 22 Giannini Hall

College of Agriculture

Berkeley $\leftarrow$, California

The limit to nonresidents of California is 10 separate issues on a single order. A list of the issues still available will be sent on request.

In our publications it is sometimes convenient to use trade names of products or equipment rather than scientific identifications. In so doing it is unavoidable in some cases that similar products which are on the market under other trade names may not be cited. No endorsement of named products is intended nor is criticism implied of similar products which are not mentioned. 